\title{
Hirano bodies differentially modulate cell death induced by tau and the amyloid precursor protein intracellular domain
}

\author{
William Spears $^{1 \dagger}$, Matthew Furgerson ${ }^{1,2 \dagger}$, John Michael Sweetnam¹, Parker Evans', Marla Gearing ${ }^{3}$,
} Marcus Fechheimer ${ }^{1}$ and Ruth Furukawa ${ }^{1 *}$

\begin{abstract}
Background: Hirano bodies are actin-rich paracrystalline inclusions found in brains of patients with Alzheimer's disease (AD), frontotemporal dementia (FTD), and in normal aged individuals. Although studies of post-mortem brain tissue provide clues of etiology, the physiological function of Hirano bodies remains unknown. A cell culture model was utilized to study the interactions of mutant tau proteins, model Hirano bodies, and GSK3 $\beta$ in human astrocytoma cells.

Results: Most tau variants showed co-localization with model Hirano bodies. Cosedimentation assays revealed this interaction may be direct, as recombinant purified forms of tau are all capable of binding F-actin. Model Hirano bodies had no effect or enhanced cell death induced by tau in the absence of amyloid precursor protein intracellular domain (AICD). In the presence of AICD and tau, synergistic cell death was observed in most cases, and model Hirano bodies decreased this synergistic cell death, except for forms of tau that caused significant cell death in the presence of Hirano bodies only. A role for the kinase GSK3 $\beta$ is suggested by the finding that a dominant negative form of GSK3 $\beta$ reduces this synergistic cell death. A subset of Hirano bodies in brain tissue of both Alzheimer's disease and normal aged individuals was found to contain tau, with some Hirano bodies in Alzheimer's disease brains containing hyperphosphorylated tau.
\end{abstract}

Conclusion: The results demonstrate a complex interaction between tau and AICD involving activation of GSK3 $\beta$ in promoting cell death, and the ability of Hirano bodies to modulate this process.

Keywords: Hirano bodies, Actin, Tau, Amyloid precursor protein, Neurodegeneration, Alzheimer's disease, Frontotemporal dementia

\section{Background}

The cause of sporadic Alzheimer's disease (AD) is unknown, and an intricate interaction between multiple genetic, epigenetic, and environmental risk factors has been proposed (for review, see [1]). However, in approximately $1 \%$ of total AD cases, studies show that neurodegeneration results from mutations in the genes encoding the amyloid precursor protein (APP), presenilin 1 (PSEN1), or PSEN2 $[2,3]$. These mutations result in altered processing of APP, increased deposition of amyloid-beta $(A \beta)$, and early onset

\footnotetext{
* Correspondence: furukawa@uga.edu

${ }^{\dagger}$ Equal contributors

'Department of Cellular Biology, University of Georgia, Athens, GA 30602, USA

Full list of author information is available at the end of the article
}

neurodegeneration. This led to the formation of the amyloid cascade hypothesis, which posits that $A \beta$ initiates a cascade of events leading to tau deposition, synaptic dysfunction and cognitive decline [4]. Intramembrane proteolysis of APP by $\gamma$-secretase also releases an intracellular fragment known as the amyloid precursor protein intracellular domain (AICD). AICD has been shown to form multi-protein complexes that regulate the induction of apoptosis (for review, see [5,6]). Multiple studies suggest that a downstream effector of AICD is the kinase GSK3 $\beta$. Studies in neuronal cell cultures and a mouse model report that AICD induces upregulation of total levels of GSK3 $\beta$ as well as increased activation, and thus induces tau hyperphosphorylation [7-9]. Abnormal tau

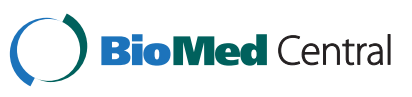

(c) 2014 Spears et al.; licensee BioMed Central Ltd. This is an Open Access article distributed under the terms of the Creative Commons Attribution License (http://creativecommons.org/licenses/by/4.0), which permits unrestricted use, distribution, and reproduction in any medium, provided the original work is properly credited. The Creative Commons Public Domain Dedication waiver (http://creativecommons.org/publicdomain/zero/1.0/) applies to the data made available in this article, unless otherwise stated. 
phosphorylation is an early marker of $\mathrm{AD}[10,11]$ and phosphorylated tau levels correlate with the severity of $\mathrm{AD}$ [12]. However, the precise mechanisms causing abnormal tau phosphorylation leading to pathological tau formation remain unclear.

Complementary to the amyloid cascade hypothesis was the discovery that mutations in tau cause a familial neurodegenerative disease called frontotemporal dementia with parkinsonism linked to chromosome 17 (FTDP-17) [13]. This disease and its sporadic (non-familial) counterparts, known as frontotemporal lobar degeneration with taupositive inclusions (FTLD-tau), are characterized pathologically by the formation of neurofibrillary tangles (NFTs) and other neuronal and glial inclusions composed of hyperphosphorylated tau [14]. A $\beta$-containing plaques found in $\mathrm{AD}$ are not considered a significant invariant pathological feature of these tauopathies. Thus, the amyloid cascade hypothesis posits that $A \beta$ acts upstream of tau to promote neurodegeneration. Nevertheless, significant plaque pathology is often reported in tauopathy patients' brain tissue [15-19].

Hirano bodies are inclusion bodies found in significant numbers in the hippocampus in patients with $\mathrm{AD}$ compared to age matched controls [20]. In addition, Hirano bodies are found in postmortem brain tissue of patients afflicted with a variety of neurodegenerative and other diseases including the tauopathies, and in normal aged individuals $[21,22]$, yet no studies to date explore the cellular basis of this finding. Although the contribution of Hirano bodies to tauopathy is unknown, cell culture and transgenic animal models of FTDP-17 suggest that alterations in the actin cytoskeleton and formation of Hirano bodies are an important event in the pathogenesis of tauopathies [23-25]. Tau has been previously shown to bind actin [26-28] and the interaction of tau with the actin cytoskeleton could play a role in disease progression. Hirano bodies are thought to be composed primarily of filamentous actin and actin-associated proteins [29-31], but they have also been shown to contain other components of the neuronal cytoskeleton such the microtubule associated protein tau [32,33]. Hirano bodies also accumulate a number of signaling proteins including the transcription factor FAC1 [34], transforming growth factor- $\beta 3$ [35], and AICD [36,37]. Interestingly, Hirano et al., observed a positive correlation between the frequency of NFTs and Hirano bodies in patient samples [38]. In that study, Hirano bodies and NFTs were often found in the same cell, although the specific isoforms, mutants, or modifications on tau and physiological consequences of this are unknown.

Early studies of Hirano bodies were reliant on immunohistochemical staining of post-mortem brain tissue due to lack of a model system to study their formation or physiological function. We have developed a cell culture model of Hirano bodies by expressing a truncated form of 34-kDa protein (CT) from Dictyostelium [39-42]. Truncation of the amino terminus of $34-\mathrm{kDa}$ protein to form CT results in a gain of function in activated actin binding activity and formation of model Hirano bodies in mammalian cells and in transgenic mice [41,43]. Model Hirano bodies mitigate the transcriptional activation activity of the APP intracellular domain (AICD), resulting in a decrease in cell death [37]. Further, model Hirano bodies decrease cell death potentiated by AICD and a pseudohyperphosphorylated (PHP) tau mimic [44].

We investigated the association of both wild type and mutant forms of tau with Hirano bodies, and their impact on cell death pathways involving tau and AICD. We report that nearly all tau isoforms and mutants tested associate with model Hirano bodies in cells, and bind to actin filaments in vitro. Cells expressing both tau and AICD exhibited cell death that was greater than the sum of that observed for tau and AICD alone. This synergistic cell death involved activation of GSK3 $\beta$, and was eliminated by the presence of model Hirano bodies. These results extend previous reports affirming a specific role for Hirano bodies in aging and disease states and provides further evidence that the presence of Hirano bodies may have an important contribution to the pathogenesis of $\mathrm{AD}$ and tauopathies such as FTDP-17.

\section{Results}

The interaction of altered forms of tau with model Hirano bodies and the impact of this interaction on disease pathways leading to cell death was investigated in this study. Mutant tau proteins were chosen on the basis of previous characterization of differential biochemical properties and their effects on cell death. Expression of mutant tau found in FTDP-17 (R5H, G272V, P301L, R406W) has differential effects on cell death when expressed in cell cultures and in various animal models of tauopathy $[24,45,46]$ and these effects may be attributable to the biochemical properties of tau $[47,48]$. The tau mutant $\Delta \mathrm{K} 280$ is representative of a group of FTDP-17 mutants previously shown to have increased susceptibility to aggregation compared to WT tau [47-49]. However, whether or not tau polymerization is directly neurotoxic continues to be a major question (for review, see [1]). Previous studies have established a cell culture, C. elegans, and mouse model of tau aggregation through expression of a tau fragment comprising only the microtubule binding domain with deletion of lysine 280 (K18 $1 \mathrm{~K} 280$ ), which has a high propensity for $\beta$-structure and aggregation [50-53]. Studies show that expression of $\mathrm{K} 18 \Delta \mathrm{K} 280$ tau is more lethal than the same fragment without the deletion of lysine 280 (K18), and causes cell death prior to the formation of mature aggregations $[50,54,55]$. The nomenclature of the tau variants and 
position of the mutation(s) used in this study are shown in Figure 1.

\section{FTDP-17 tau mutants and Hirano bodies differentially modulate cell death}

The effect of FTDP-17 tau mutants (R5H, G272V, P301L, R406W), 352PHP, and truncated K18 and K18 $\Delta$ K280 tau on cell death in the presence of model Hirano bodies was investigated. As expected, exogenous expression of wild type tau, 352PHP, and FTDP-17 tau mutants alone, R5H, R406W, G272V, or P301L did not produce significant cell death (Figure 2). Consistent with previous reports, expression of $\mathrm{K} 18 \Delta \mathrm{K} 280$ resulted in significant cell death compared to expression of K18 (Figure 2D, gray bars $\left.{ }^{* * *} \mathrm{p}<0.001\right)$. Coexpression of either 352WT, $441 \mathrm{WT}, 352 \mathrm{PHP}, \mathrm{R} 5 \mathrm{H}, \mathrm{R} 406 \mathrm{~W}, \mathrm{~K} 18$, or K18 $\mathrm{K} 280$ tau in the presence of model Hirano bodies resulted only in background levels of cell death (Figure 2AB, check bars). In contrast, expression of either G272V ( ${ }^{* *} \mathrm{p}<$ $0.01)$ or P301L $(* * \mathrm{p}<0.001)$ in the presence of model Hirano bodies resulted in significant potentiation of cell death (Figure 2C, check bars).

\section{Actin binding}

Tau has been previously shown to bind F-actin - albeit not to saturation - and form F-actin bundles in solution [26-28]. We determined the relative F-actin binding for wild type tau and mutant forms of tau to investigate whether the strength of actin binding may correlate with cell death induced by tau and Hirano bodies. Using recombinant protein purified from E.coli and cosedimentation with mixtures of F-actin, wild type and mutant forms of tau do not achieve saturation binding to F-actin as shown in Figure 3. R406W, G272V, P301L, and $441 \mathrm{WT}$ bind F-actin better than 352PHP and R5H, which are greater than 352WT (Figure 3). This result is consistent with previous results of wild type recombinant tau [27].

We investigated whether tau has an effect on formation of model Hirano bodies since a prior report found that tau promotes the formation of Hirano bodies [56]. Transient expression of CT-GFP to induce model Hirano bodies and either 352WT, 441WT, 352PHP, or P301L for $48 \mathrm{~h}$ did not cause a change in the size of model Hirano bodies (Additional file 1). Thus, Hirano bodies can form in the absence of tau, and the presence of various forms of tau does not modulate the formation of Hirano bodies.

\section{Hirano bodies, tau, and AICD}

Since previous reports have indicated that model Hirano bodies protected against AICD-induced cell death in the presence of 352WT or 352PHP [44], we investigated whether model Hirano bodies would have an effect on cell death induced by FTDP-17 tau (R5H, G272V, P301L, $\mathrm{R} 406 \mathrm{~W})$, or truncated tau (K18 or K18 $\mathrm{K} 280)$ in the presence of AICD. Expression of AICD resulted in modest levels of cell death (Figure 2A, white bars), and the presence of model Hirano bodies significantly lowered this death (white bars, " $\mathrm{p}<0.05$ ). Coexpression of either $352 \mathrm{WT} / \mathrm{AICD}$ or $441 \mathrm{WT} / \mathrm{AICD}$ (black bars) caused an incremental increase in cell death that is similar to what is expected from the additive effects of AICD alone and wild type tau alone (see Table 1). In contrast, a marked potentiation in cell death was observed upon coexpression of 352PHP/AICD (black bars, Table 1) consistent with previous data [44]. The potentiation of cell death is a synergistic interaction between AICD and 352PHP since the predicted amount of cell death due to AICD alone plus that obtained with $352 \mathrm{PHP}$ alone is significantly less than observed when the two are present together (Table 1). The presence of model Hirano bodies protected against cell death induced by either 352WT/AICD (stripe bar, $\left.{ }^{* * * *} \mathrm{p}<0.001\right)$ or $441 \mathrm{WT} / \mathrm{AICD}$ (stripe bar, ${ }^{* *} \mathrm{p}<0.01$ ), or 352PHP/AICD (stripe bar, $*$ p $<0.01$ ).

The effect of FTDP-17 tau mutants on AICD-induced cell death in the presence or absence of model Hirano bodies was investigated. Similar to 352PHP tau, FTDP17 tau mutants (R5H, G272V, P301L, R406W) enhance cell death in synergy with AICD (Figure 2B,C, black bars). The amount of cell death observed is greater than obtained from AICD alone plus that of tau alone (Table 1). The presence of model Hirano bodies protected from cell death due to either AICD/R5H or AICD/R406W (Figure $2 \mathrm{~B}$, stripe bars ${ }^{* *} \mathrm{p}<0.01$ ). However, in cells

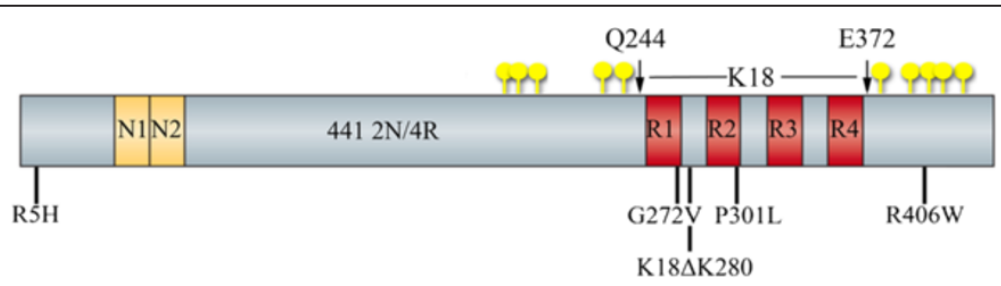

Figure 1 Schematic illustration of tau isoforms, phosphorylation sites and mutations. Point mutations R5H, G272V, P301L, and R406W were created in the 2N4R (441) tau isoform. Arrows represent boundaries of K18 (amino acids 244-372) [54]. N1 and N2 represent N-terminal exons 1 and 2. R1, R2, R3, and R4 represent microtubule binding domain repeats 1-4. Yellow circles designate 10 serine/threonine to glutamic acid mutations that occur in 352PHP tau [101]. This mutant was created in the 352 tau isoform lacking N1, N2, and R2. 


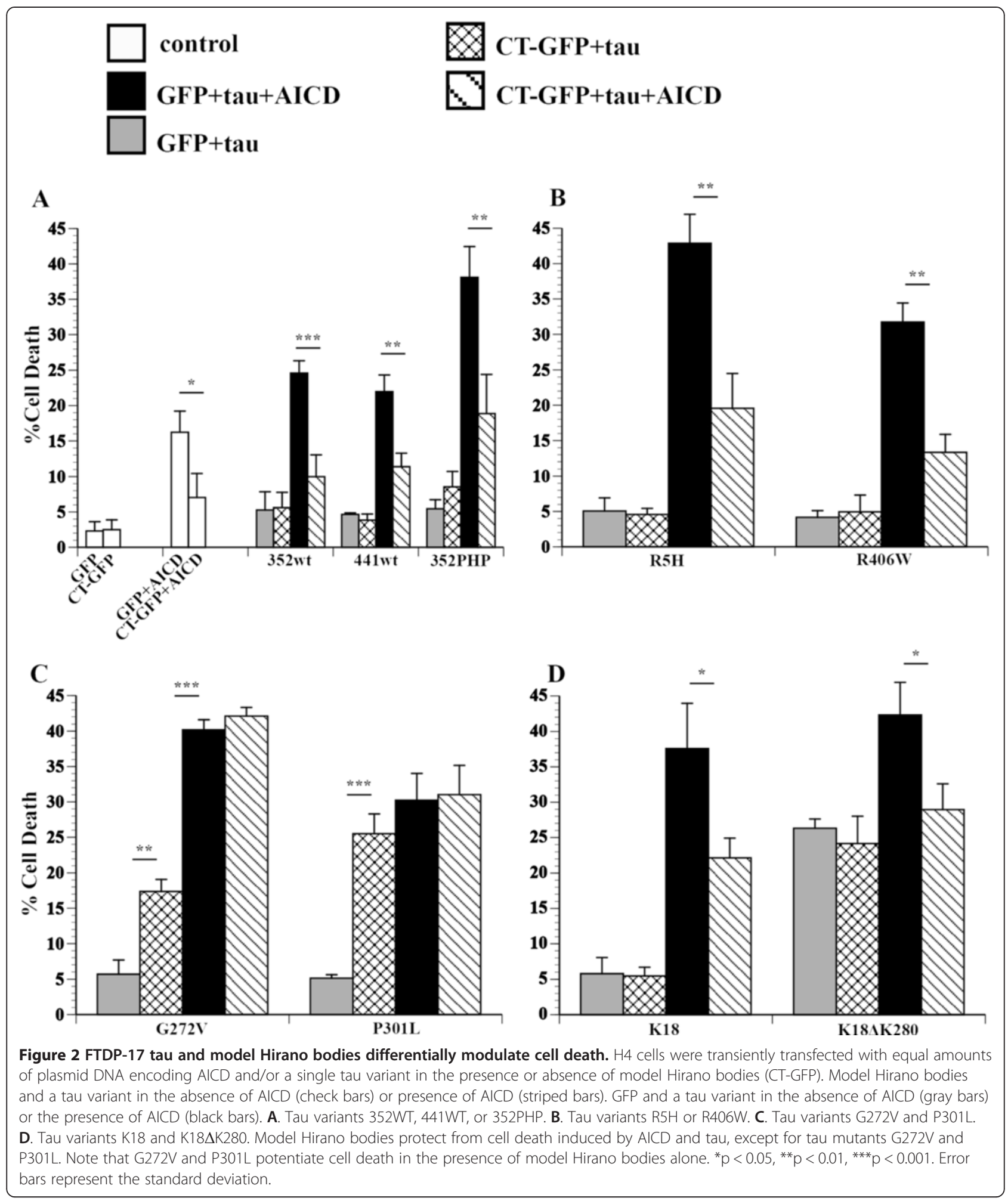

expressing either G272V/AICD or P301L/AICD, model Hirano bodies had no effect on cell death (Figure $2 \mathrm{C}$, stripe bars). Expression of $\mathrm{K} 18$ and $\mathrm{K} 18 \Delta \mathrm{K} 280$ with AICD increased cell death synergistically and additively, respectively (black bars, ${ }^{*} \mathrm{p}<0.05$; Table 1 ). The presence of model Hirano bodies lowered cell death (stripe bars *p < 0.05) for both K18 and K18 $\mathrm{K} 280$. These data suggest that model Hirano bodies have a differential effect on cell death induced by tau and/or AICD, depending on the tau variant used. 


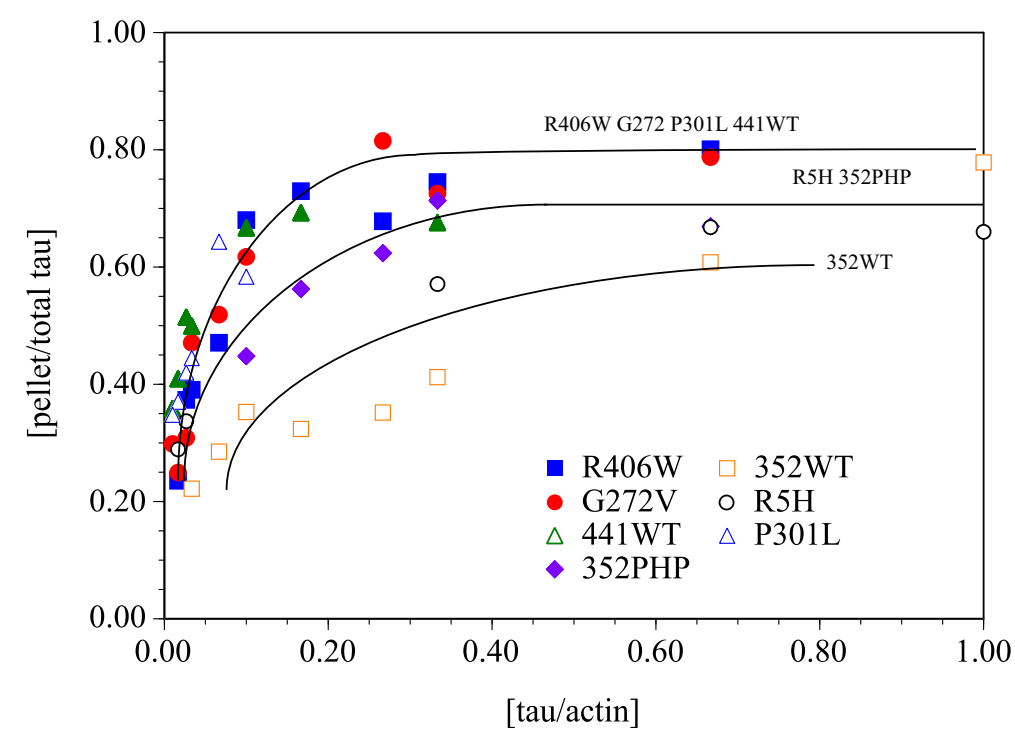

Figure 3 Relative binding of recombinant tau to F-actin. Tau binds differentially to F-actin with binding of R406W (blue square), G272V (red circle), P301L (blue triangle), and 441WT (green triangle) > 352PHP (purple diamond) and R5H (black circle) > 352WT (orange square). The curves are to aid the reader and do not indicate biochemical binding curves. The standard deviations were not shown for clarity.

Collectively, the synergistic versus additive cell death of co-expression of AICD and tau variants suggests a connection by one or more molecular pathways. The effect of Hirano bodies on cell death may affect AICD, or tau, and/ or the synergy that arises from their interaction. Possible routes of this interaction could involve activation of the protein kinase GSK3 $\beta$, phosphorylation of tau, binding of tau to F-actin, or differential aggregation kinetics of the tau variants.

Hirano bodies differentially influence cell death induced by GSK3 $\beta$ and tau

GSK3 $\beta$ has been implicated in the pathogenesis of AD (for review, see [57]). Specifically, GSK3 $\beta$ is thought to become upregulated and/or activated by $\mathrm{A} \beta, \mathrm{AICD}$, and the c-terminal 31 amino acids of APP (c31), triggering a cascade of signaling events leading to tau hyperphosphorylation, apoptosis, and cell death $[7,9,58]$. The contribution of GSK3 $\beta$ and tau to cell death in the presence of model Hirano bodies was investigated using a constitutively active and a dominant negative form of GSK3 $\beta$. Exogenous expression of a constitutively active mutant of GSK3 $\beta$ (S9A) alone causes cell death similar to that of AICD, and the presence of model Hirano bodies has no effect on this death (Figure 4A, white bars). In contrast, exogenous expression of GSK3 $\beta$ (S9A) in the presence of $352 \mathrm{WT}$ or $352 \mathrm{PHP}$ causes significant potentiation of cell death compared to GSK3 $\beta$ (S9A) alone (Figure 4A, black bars *** $\mathrm{p}<0.001$ or **p $<0.01$, respectively, Table 2). Interestingly, although $352 \mathrm{WT}$ and 352PHP produce similar amounts of cell death under these conditions, $441 \mathrm{WT}$ expression causes only an incremental increase

Table 1 Additive versus synergistic cell death induced by co-expression of AICD and tau

\begin{tabular}{|c|c|c|c|}
\hline Tau & $\%$ Cell death (Additive) = GFP/AICD + GFP/tau & $\%$ Cell death \pm SD $($ Actual $)=$ GFP $/$ AICD $/$ tau & $\mathrm{p}$ value \\
\hline 352tauWT & $22.3 \% \pm 1.46$ & $24.6 \% \pm 1.74$ & N.S. \\
\hline 441 tauWT & $20.9 \% \pm 2.78$ & $22.0 \% \pm 2.36$ & N.S. \\
\hline 352tauPHP & $21.7 \% \pm 1.98$ & $38.1 \% \pm 4.35$ & $\mathrm{p}<0.05$ \\
\hline R5H & $21.3 \% \pm 2.49$ & $42.9 \% \pm 4.09$ & $\mathrm{p}<0.01$ \\
\hline K18 & $22.0 \% \pm 4.24$ & $39.0 \% \pm 6.98$ & $\mathrm{p}<0.05$ \\
\hline $\mathrm{K} 18 \Delta \mathrm{K} 280$ & $42.5 \% \pm 4.28$ & $42.3 \% \pm 4.61$ & N.S. \\
\hline P301L & $21.4 \% \pm 2.97$ & $30.2 \% \pm 3.79$ & $\mathrm{p}<0.05$ \\
\hline G272V & $21.9 \% \pm 2.73$ & $40.2 \% \pm 1.40$ & $\mathrm{p}<0.01$ \\
\hline R406W & $20.4 \% \pm 3.93$ & $31.7 \% \pm 2.70$ & $\mathrm{p}<0.05$ \\
\hline
\end{tabular}

Values of cell death obtained when GFP/AICD or GFP/tau transiently expressed were added together and compared to the actual values of cell death obtained when GFP/AICD/tau were co-expressed. Synergistic cell death (bold entries) was observed when AICD was co-expressed with 352PHP, R5H, K18, P301L, G272V, or R406W. N.S. = not significant. 


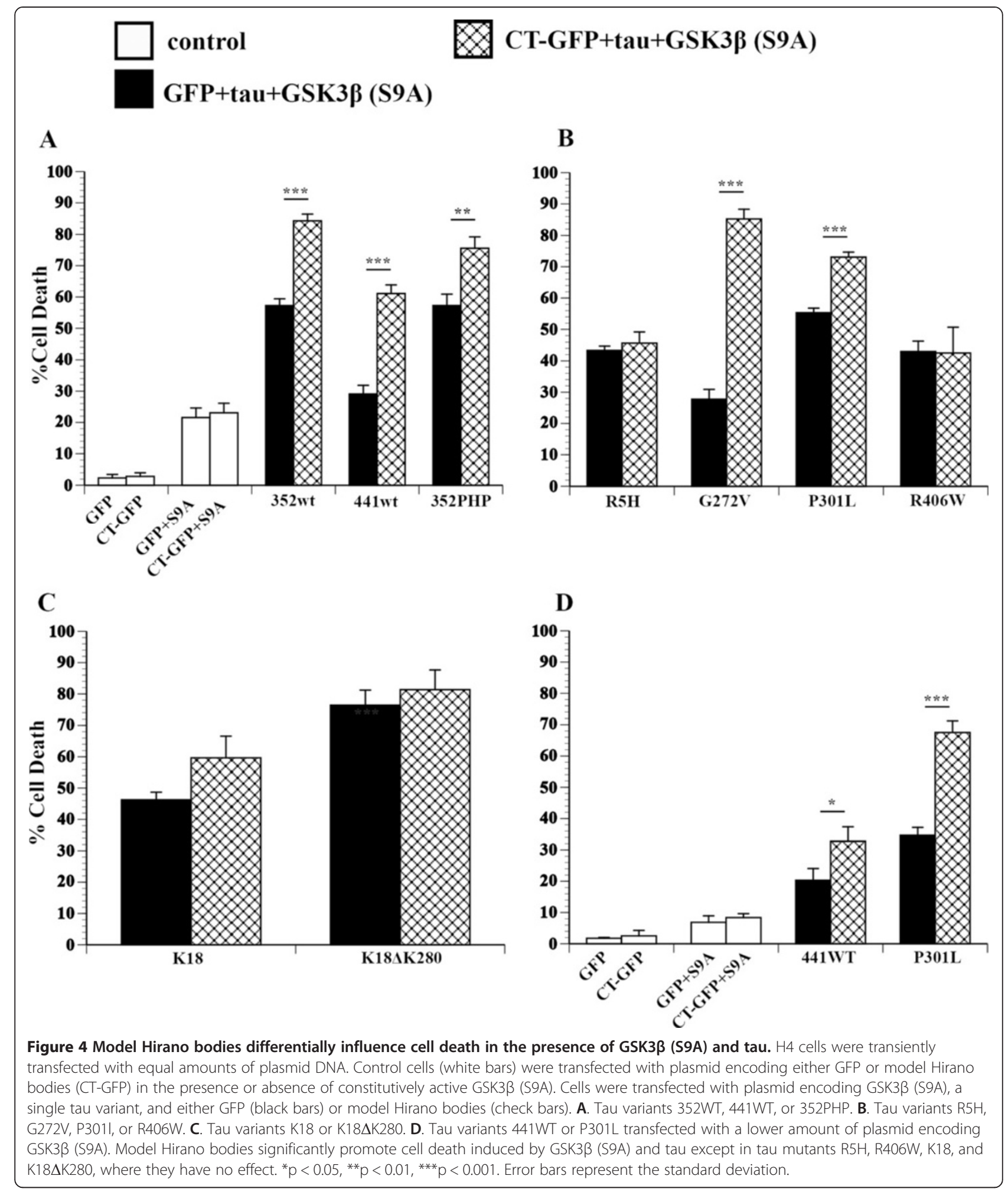

in cell death when expressed with GSK3 $\beta$ (S9A), which is not significantly different from that expected from cell death due to 441WT alone + GSK3 $\beta$ (S9A) alone (Figure 4A, black bar; Table 2). Exogenous expression of
GSK3 $\beta$ (S9A) with either WT tau isoform or 352PHP in the presence of model Hirano bodies causes even further potentiation of cell death (Figure 4A, check bars, ${ }^{* * * *} \mathrm{p}<0.001$ or $*$ p $<0.01$ ). 
Table 2 Additive versus synergistic cell death induced by co-expression of tau and GSK3 $\beta$ (S9A)

\begin{tabular}{|c|c|c|c|}
\hline Tau & $\%$ Cell death (Additive) $=$ GFP/GSK3 $\beta(S 9 A)+$ GFP/tau & $\%$ Cell death $($ Actual $)=$ GFP $/$ GSK3 $\beta(S 9 A) /$ tau & $\mathrm{p}$ value \\
\hline 352tauWT & $24.1 \% \pm 1.44$ & $57.3 \% \pm 1.74$ & $p<0.005$ \\
\hline 441 tauWT & $24.7 \% \pm 0.95$ & $29.1 \% \pm 2.77$ & N.S. \\
\hline 352tauPHP & $25.5 \% \pm 1.52$ & $49.8 \% \pm 3.63$ & $\mathrm{p}<0.005$ \\
\hline R5H & $25.1 \% \pm 1.62$ & $43.4 \% \pm 1.37$ & $\mathrm{p}<0.005$ \\
\hline K18 & $25.9 \% \pm 1.40$ & $46.3 \% \pm 2.44$ & $p<0.005$ \\
\hline $\mathrm{K} 18 \Delta \mathrm{K} 280$ & $46.4 \% \pm 1.00$ & $76.4 \% \pm 4.84$ & $\mathrm{p}<0.005$ \\
\hline P301L & $25.2 \% \pm 1.37$ & $55.3 \% \pm 1.45$ & $\mathrm{p}<0.005$ \\
\hline G272V & $25.8 \% \pm 2.88$ & $27.8 \% \pm 3.13$ & N.S. \\
\hline R406W & $24.3 \% \pm 1.14$ & $43.0 \% \pm 3.33$ & $\mathrm{p}<0.005$ \\
\hline
\end{tabular}

Values of cell death obtained when GFP/GSK3 3 (S9A) or GFP/tau transiently expressed were added together and compared to the actual values of cell death obtained when GFP/GSK3 $\beta$ (S9A)/tau were co-expressed. Synergistic cell death (bold entries) was observed when GSK3 3 (S9A) was co-expressed with 352PHP, $\mathrm{R} 5 \mathrm{H}, \mathrm{K} 18, \mathrm{~K} 18 \Delta \mathrm{K} 280, \mathrm{P} 301 \mathrm{~L}$, or R406W. Interestingly, cell death in the presence of G272V was not affected by the presence of GSK3 $\beta$ (S9A). N.S. = not significant.

The effect of FTDP-17 mutant tau expression on cell death induced by GSK3 $\beta$ (S9A) and model Hirano bodies was investigated. Exogenous expression of tau mutants $\mathrm{R} 5 \mathrm{H}, \mathrm{P} 301 \mathrm{~L}$, and R406W in the presence of GSK3 3 (S9A) increased cell death synergistically compared to the sum of that observed with expression of GSK3 $\beta$ (S9A) and tau alone (Figure 4B, black bars; Table 2). However, expression of $\mathrm{G} 272 \mathrm{~V}$ tau in the presence of GSK3 $\beta$ (S9A) resulted in only additive increases in cell death compared to expression of GSK3 $\beta$ (S9A) alone (Figure 4AB, Table 2). We also observed differences in the ability of model Hirano bodies to modulate cell death in the presence of FTDP-17 mutant tau and GSK3 3 (S9A). Model Hirano bodies enhanced cell death in the presence of GSK3 $\beta$ (S9A)/G272V tau and GSK3 $\beta$ (S9A)/P301L tau (Figure 4B, check bars $*$ \% $<0.001)$, a result that occurred when either G272V or P301L was expressed with model Hirano bodies. However, model Hirano bodies had no effect on cell death induced by GSK3 3 (S9A)/R5H tau or GSK3 3 (S9A)/ R406W tau (Figure 4B, check bars).

GSK3 $\beta$ (S9A) also significantly enhanced cell death in the presence of $\mathrm{K} 18$ or $\mathrm{K} 18 \Delta \mathrm{K} 280$ compared to the sum of the expression of GSK3 $\beta$ (S9A) and tau alone (Figure 4C, black bars *** $\mathrm{p}<0.001$; Table 2). Model Hirano bodies did not have a statistically significant effect on this cell death (Figure 4C, check bars). We also measured cell death under conditions in which expression of GSK3 $\beta$ (S9A) did not induce significantly greater levels of cell death than GFP controls (Figure 4D), showing that GSK3 $\beta$ (S9A)-induced cell death is dose dependent. Similar to previous results (Figure $4 \mathrm{~A}-\mathrm{C}$ ), exogenous expression of GSK3 $\beta$ (S9A)/441WT or GSK3 $\beta$ (S9A)/P301L potentiated cell death compared to GSK3 $\beta$ (S9A) alone (Figure 4D, black bars). In addition, the presence of model Hirano bodies further increased this cell death compared to expression of GSK3 $\beta$ (S9A)/441WT (check bars, " $\mathrm{p}<0.05$ ) or GSK3 $\beta$ (S9A)/P301L (check bars *** ${ }^{*}<0.001$ ). These results show that model Hirano bodies are not protective against cell death induced by GSK3 $\beta$ and tau, and depending on the mutation, may further increase cell death.

The contribution of dominant negative GSK3 $\beta$ (K85A) $[7,59]$ was used to test the role of GSK3 $\beta$ in cell death induced by tau and model Hirano bodies. GSK3 3 (K85A) was transiently co-expressed with model Hirano bodies in the presence and absence of G272V (Table 3). The unexpectedly higher level of cell death due the presence of G272V and model Hirano bodies was reduced in the presence of GSK3 $\beta$ (K85A) to that expected from the control GFP/G272V + GFP/GSK3 $3($ K85A) (Table 3, p < 0.02). This result shows an interaction between $\mathrm{F}$-actin and tau that is more complex than F-actin binding alone and that phosphorylation of tau likely plays a role in cell death.

To determine whether cell death induced by combinations of AICD and tau involve activation of GSK3 $\beta$ and the phosphorylation state of tau, the effect of a dominant negative GSK3 $\beta$ (K85A) was investigated (Figure 5). Expression of GSK3 $\beta$ (K85A) with GFP does not significantly increase the cell death due to GFP alone (Figure 4, white bars). Further, expression of AICD induces death of approximately $17 \%$ of cells, and this number is not significantly changed in the presence of GSK3 $\beta$ (K85A) (Figure 5A, white bars). Thus, cell death due to AICD alone does not require activation by GSK3 $\beta$. Cell death

Table 3 The effect of tau phosphorylation on cell death in the presence of model Hirano bodies

\begin{tabular}{|c|c|}
\hline Sample & $\%$ Cell death \\
\hline Hirano body/GSK3 $\beta(K 85 A)$ & $4.20 \pm 0.77$ \\
\hline Hirano body/G272V & $17.90 \pm 2.59$ \\
\hline Hirano body/G272V/GSK3 $\beta(K 85 A)$ & $10.20 \pm 1.35$ \\
\hline GFP/G272V & $4.75 \pm 0.74$ \\
\hline GFP/G272V/ GSK3ß(K85A) & $5.80 \pm 0.56$ \\
\hline GFP/G272V + GFP/ GSK3ß(K85A) & $8.95 \pm 2.06$ \\
\hline
\end{tabular}

Expression of GSK3 $\beta(\mathrm{K} 85 \mathrm{~A})$ reduced the synergistic cell death observed when both G272V and model Hirano bodies are present, to an additive effect, implying that the phosphorylation state is important. 


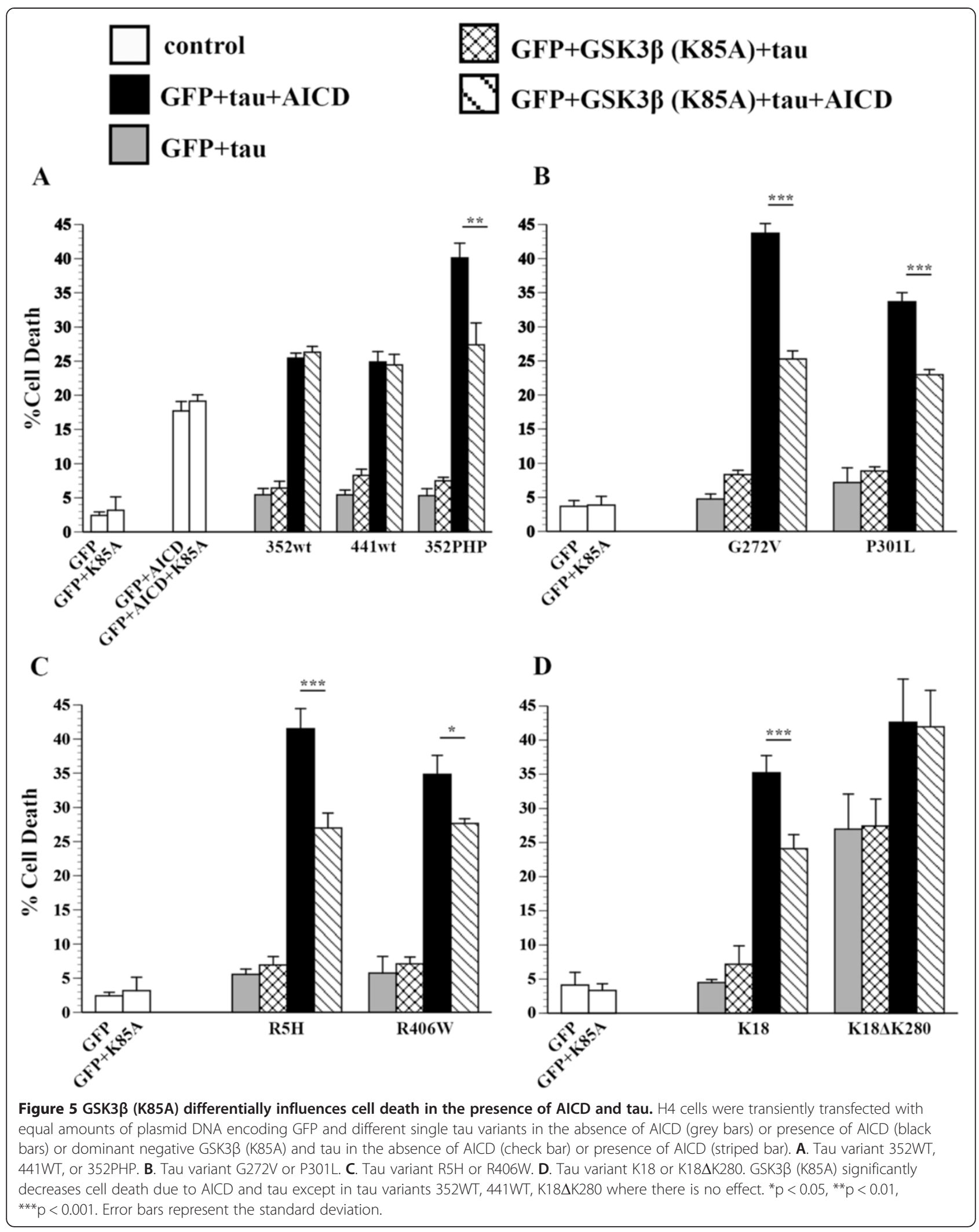


due to wild type, 352PHP, FTDP-17 mutants, and K18 and $\mathrm{K} 18 \Delta \mathrm{K} 280$ was unaffected by expression of GSK3 $\beta$ (K85A) (Figure 5A and D, grey and checked bars). Cell death due to tau + AICD was suppressed by expression of GSK3 $\beta$ (K85A) for 352PHP, G272V, P301L, R5H, and R406W, and K18 (Figure 5A-D, black and striped bars). However, expression of GSK3 $\beta$ (K85A) had no effect on cell death induced by AICD/352WT, AICD/441WT, or $\mathrm{AICD} / \mathrm{K} 18 \Delta \mathrm{K} 280$ (Figure $5 \mathrm{~A}$ and D, black and striped bars). Interestingly, cell death of all tau forms + AICD that were suppressed by expression of GSK3 $\beta$ (K85A) showed synergistic cell death in the presence of GSK3 $\beta$ (S9A) (Table 2). These results imply that synergistic cell death due to AICD and tau involve activation of GSK3 $\beta$, and that phosphorylation of tau is an important factor to cell death. Cell death due to tau forms + AICD that were not suppressed by expression of GSK3 $\beta$ (K85A) had levels of cell death that was not significantly different from the sum of that observed with tau and AICD separately.

\section{Phosphorylation of tau}

Results of cell viability in the presence of GSK3 $\beta$ (K85A) suggest that 352PHP, R5H, R406W, G272V, and P301L become phosphorylated by GSK3 $\beta$ in the presence of AICD or CT-GFP. Previously, others have reported that AICD is capable of increasing cellular levels of GSK3 $\beta$ [7-9]. Therefore, western blot analysis was performed to determine whether the presence of AICD and/or CTGFP impact the amount of GSK3 $\beta$ protein in our cell culture system. The presence of exogenous AICD increases total GSK3 $\beta$ levels above that of untransfected cells and also of cells expressing tau only (Figure 6A). Furthermore, expression of CT-GFP in the presence of AICD and tau reduces the amount of GSK3 $\beta$ to that of the control (Figure 6A). The increase of tau-induced cell death due to the presence of G272V or P301L and CT-GFP was reduced in the presence of GSK3 $\beta$ K85A (Figure 5), suggesting CT-GFP may promote phosphorylation of these tau mutants. To test this hypothesis, western blot analysis was performed on different tau mutants to determine if the presence of CT-GFP increases phosphorylation at specific amino acids. 441WT, R406W, and $\mathrm{R} 5 \mathrm{H}$ tau showed no increase in phosphorylation at Ser199, Ser202, or Thr231 in the presence of CT-GFP (Figure 6B). Interestingly, both P301L and G272V have increased phosphorylation at Ser199 and Ser202 and Thr231 in the presence of CT-GFP (Figure 6B). P301L and G272V exhibited synergistic cell death in the presence of CT-GFP (Figure 2C). These results show that the ability of specific mutant tau proteins to induce cell death in the presence of AICD or CT-GFP is due to GSK3 $\beta$ phosphorylation of tau.

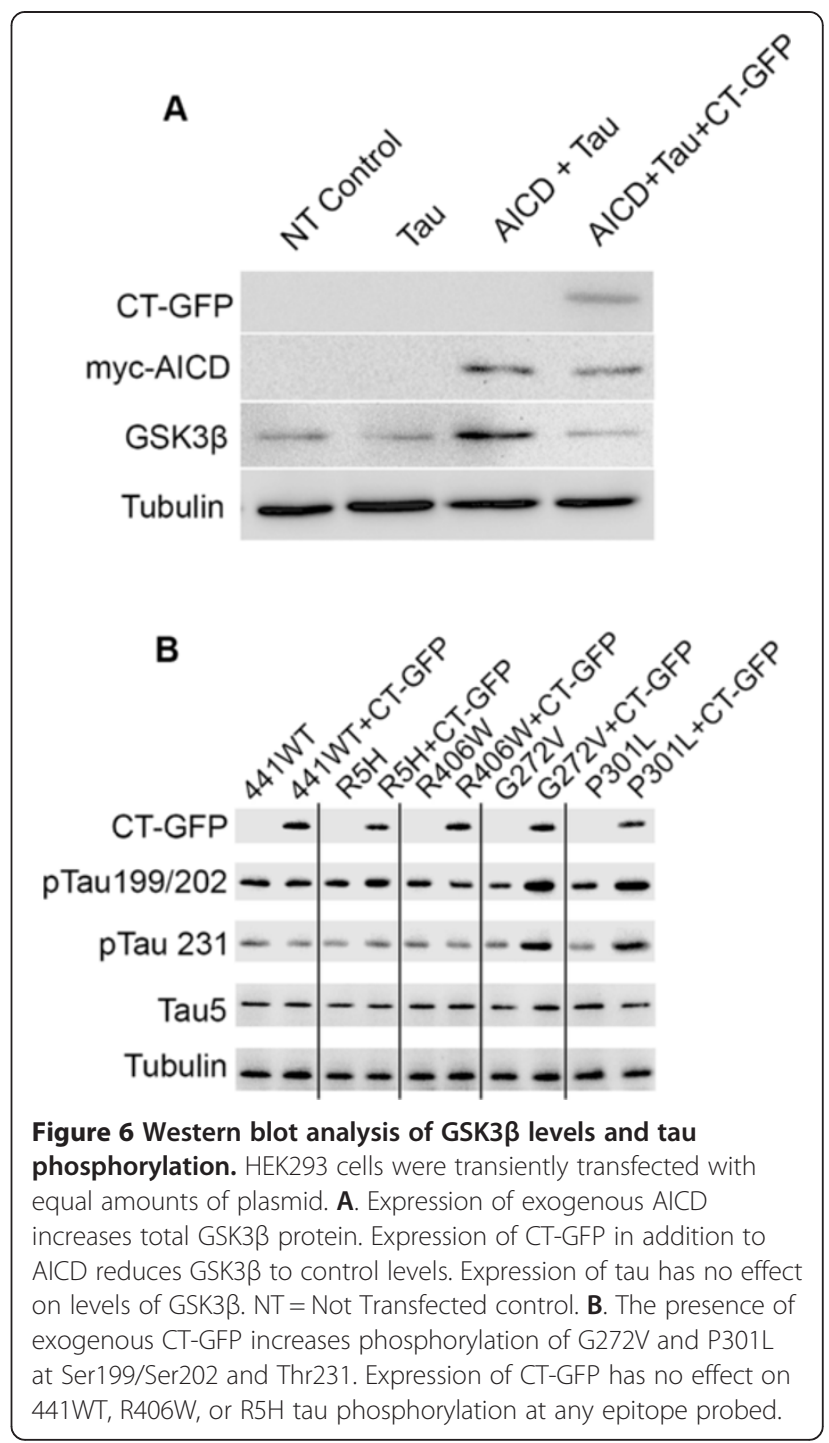

Localization of tau and model Hirano bodies

Since preferential accumulation of different forms of tau might indicate physiological function of Hirano bodies, mutant tau and model Hirano body localization was investigated. H4 cells were transiently transfected with CT-GFP to induce model Hirano bodies in the absence or presence of one of the following FLAG-tagged tau constructs: 441WT, 352WT, R5H, G272V, P301L, R406W, 352PHP, K18 1 K280 and K18. All FTDP-17 mutant tau proteins as well as WT tau isoforms were present throughout the model Hirano body or formed a ring-like structure around the periphery of the model Hirano body shown in Figure 7. The exception was 352PHP, which was diffusely localized throughout the cell. Further, truncated tau mutants (K18 or K18 K 280 ) also showed a strong nuclear localization. These results show that regardless of mutations, tau shows enrichment at sites of F-actin accumulation. However, 


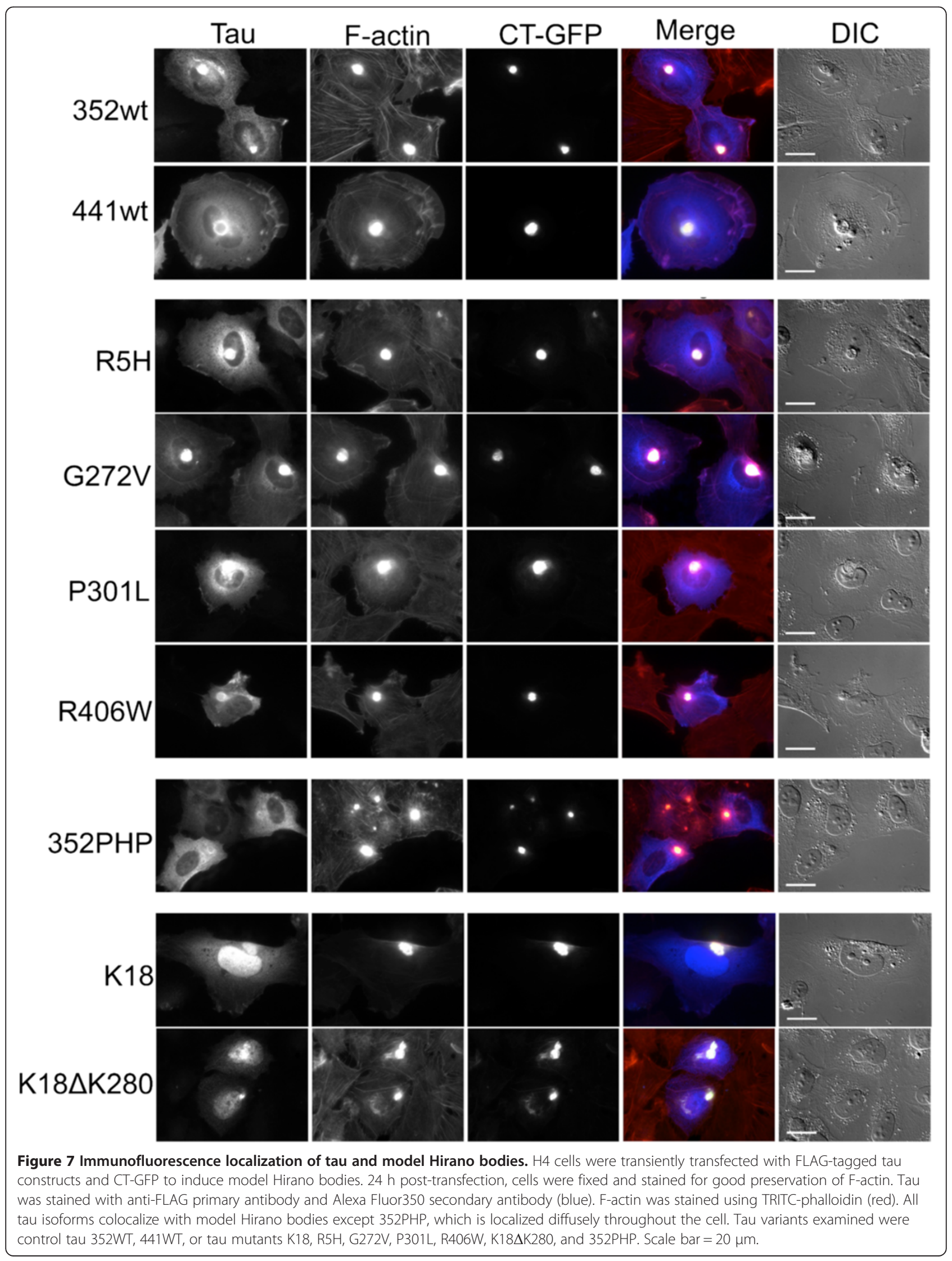


hyperphosphorylation may decrease this association, as shown for 352PHP tau.

Localization of tau in human brain tissue was performed to confirm that tau is present in Hirano bodies. In $\mathrm{AD}$ and control brain sections, 4.1 and $2.7 \%$ of Hirano bodies are well stained for tau, respectively (Figure 8). Localization of phosphorylated tau (pTau199/202) to Hirano bodies was observed only in AD brain sections and comprised $2.9 \%$ of the total Hirano bodies. These findings are in agreement with prior studies that report tau localized in a fraction of all Hirano bodies in human hippocampus [32,33].

\section{Discussion}

Tau contributes significantly to neurodegeneration in FTDP-17, Alzheimer's disease and other tauopathies by aggregating to form oligomers, paired helical filaments (PHF), and eventually large aggregates including neurofibrillary tangles (NFTs). In vitro, formation of oligomers and higher order polymers of tau is thought to occur through the process of nucleation, elongation, and/or autocatalytic growth [60,61]. Regulatory pathways may influence the availability of free tau, its phosphorylation state, propensity to aggregate, and inducers of aggregation. Dissecting the formation of oligomeric and higher order polymers of tau in vivo and their contribution to cell death require probing these pathways. In this study we have investigated the role of Hirano bodies in modulating tau localization and cell death due to tau.

\section{Proposed cell death pathway involving Hirano bodies, tau, AICD, and GSK3 $\beta$}

The role of tau in cell death induced by the presence or absence of model Hirano bodies and/or AICD is a complex intersection of several variables: 1) affinity of tau for actin; 2) the phosphorylation state and location of the phosphorylated amino acids on tau; and 3) the kinetics and propensity of tau to self-aggregate that could depend on phosphorylation or other modification. As shown in Figure 9, AICD causes significant cell death when expressed alone. Similarly, expression of K18 $\Delta$ K280 causes significant cell death unlike expression of all other forms of tau tested (Figure 9). When coexpressed with AICD, all tau mutants expressed except for 441WT, $352 \mathrm{WT}$, and $\mathrm{K} 18 \Delta \mathrm{K} 280$ produced synergistic cell death (Figure 9C). This cell death was ameliorated in the presence of model Hirano bodies, except in the case of P301L or G272V tau (red lines). This could be due to reduction of AICD or tau through indirect or direct binding to F-actin in the model Hirano bodies and/or reduction of GSK3 $\beta$ (Figure 6A) and thus affecting the phosphorylation state of tau (Figure 6B). Interestingly, the expression of model Hirano bodies and P301L or G272V tau led to significant cell death in the absence of AICD (Figure 2C). This process could be facilitated by a combination of binding to F-actin, increased phosphorylation that reduces F-actin binding, and subsequent tau aggregation. The affinity of tau for F-actin itself is insufficient as R406W and $441 \mathrm{WT}$ bound F-actin as well as G272V and P301L.

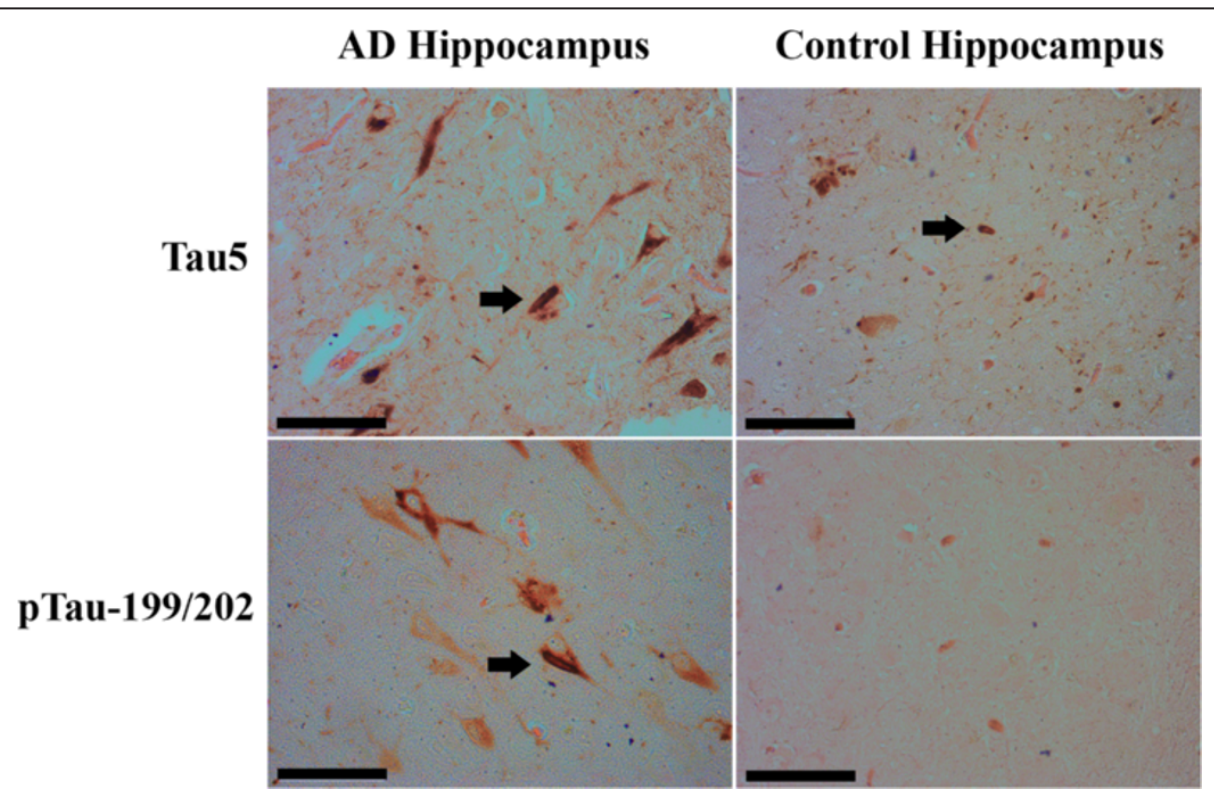

Figure 8 Immunohistochemistry localization of tau and Hirano bodies in human brains. Immunohistochemistry was performed on paraffin embedded human brain sections using Tau5 or pTau-199/202 antibodies following an eosin counterstain to visualize Hirano bodies (arrows). Tau5 antibodies colocalized with Hirano bodies in both Alzheimer diseased and control brains while pTau-199/202 colocalized with Hirano bodies only in Alzheimer diseased brains. Scale bar $=50 \mu \mathrm{m}$ 


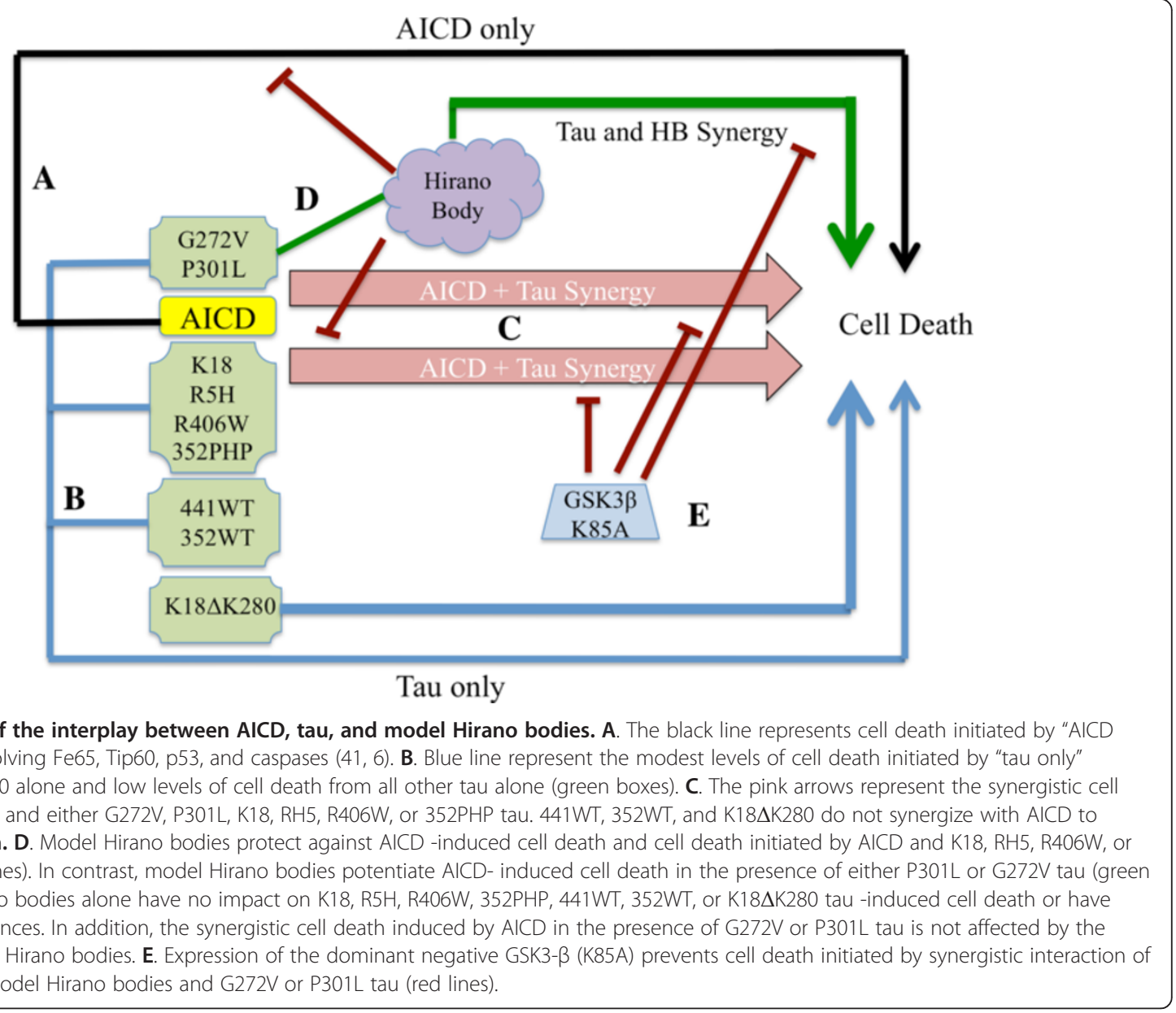

We also find that expression of a dominant negative form of GSK3 $\beta$ mitigates cell death due to the synergistic effect of AICD and tau in most cases (Figure 5, Figure 9E). This result underscores the importance of GSK3 3 activation and tau phosphorylation in the synergistic interaction of AICD and tau. In support of this, expression of dominant negative GSK3 $\beta$ (K85A) does not reduce cell death due to expression of AICD alone, or AICD and K18 $\Delta \mathrm{K} 280$, as most GSK3 $\beta$ phosphorylation sites are absent from this mutant. We show that expression of GSK3 $\beta$ (K85A) ameliorates cell death due to $\mathrm{G} 272 \mathrm{~V}$ in the presence of Hirano bodies, further substantiating the role of GSK3 $\beta$ phosphorylation in our system, even in the absence of exogenously expressed AICD. In summary, these results support the assertion that a combination of tau phosphorylation and aggregation leads to cell death, which may be either enhanced or mitigated by the presence of model Hirano bodies depending on the form of tau and state of its modification.

These new results resolve an apparent contradiction in previous literature. Expression of mutant forms of tau were shown to induce cell death only after overexpression of actin and subsequent formation of actin-rich structures in a Drosophila model [24]. However, model Hirano bodies were previously reported to reduce toxicity associated with tau under certain conditions [44]. Here we show that Hirano bodies can both promote and protect against cell death initiated by tau depending on the type of tau expressed.

\section{Tau and actin}

Multiple studies point to the role of tau as an actin binding protein [25-28,62-66]. However, this idea is not without controversy. Studies of tau-actin interactions utilize a range of experimental approaches that yield differential results [67]. Tau has been shown to bind and bundle actin in vitro $[24,27,28,62]$. Tau bound weakly to actin and did not reach saturation [27]. In competitive binding studies with actin, the preferred substrate of tau is tubulin polymerized into microtubules [27,65]. Our study is the first to show that all tau mutants tested are able to bind to F-actin with the resultant binding R406W, G272V, P301L, and 441WT > 352PHP and R5H > 352WT (Figure 3). R406W, G272V, and P301L have the highest affinity for F-actin yet only G272V and P301L potentiate cell death in the presence of model Hirano bodies and/or 
AICD (Figure 2, Table 1). The differences in F-actin binding affinity of the various tau mutants does not explain the differential effect of tau on cell death in the presence of model Hirano bodies. However, since recombinant protein produced in E.coli was used, the impact of tau post-translational modifications on F-actin binding was not measured. Other results reported in this study imply that the phosphorylation state of tau is important. In the presence of constitutively active GSK3 $\beta$ (S9A), model Hirano bodies potentiate cell death in the presence of tau (see Table 2). In addition, only a small percentage of Hirano bodies in AD brain contain phosphorylated tau (Figure 8). Another group was unable to detect pTau-202/205 in Hirano bodies from Alzheimer's patients [68]. It is possible that colocalization of tau with Hirano bodies varies from patient to patient and is heavily influenced by post-translational modification, and aggregation state given that Hirano bodies frequently occur in NFTcontaining neurons [38]. Consistent with this hypothesis, others have shown that phosphorylation of tau at certain sites reduces, but may not abolish its ability to associate with actin filaments [69]. Conversely, studies have suggested that minor phosphorylation of certain residues may enhance actin binding [24,27,70]. This suggests a complex, dynamic relationship between tau and actin. This may explain why 352PHP binds F-actin in vitro (Figure 3), but does not co-localize with model Hirano bodies (Figure 7). In vivo, tau association with actin has been shown to be critical for tau-induced neurodegeneration [24]. We cannot rule out that other modes of actin and tau interaction may be occurring such as intermediate binding proteins or other protein modifications. For example, tau also binds to Fe65 [71], and Fe65 is known to be enriched in Hirano bodies [37].

\section{Phosphorylation of tau}

Studies characterizing FTDP-17 tau mutants demonstrated that tau was highly phosphorylated, and depending on the mutation, differentially phosphorylated [72-74]. This differential phosphorylation also affects the ability of tau and its mutants to bind to microtubules [75], affects microtubule dynamic instability, and promotes microtubule assembly (for a review, see [76]). It is also well known that tau phosphorylation at multiple sites in vivo decreases its association with microtubules $[67,77]$, thus making tau available to aggregate. Hyperphosphorylated tau has a tighter, more folded conformation and in some cases, an increased propensity to aggregate $[14,74,78-83]$.

In all tau constructs tested except for R5H, R406W, $\mathrm{K} 18$, or $\mathrm{K} 18 \Delta \mathrm{K} 280$, expression of exogenous constitutively active GSK3 $\beta$ (S9A) and tau in the presence of model Hirano bodies strongly potentiated cell death compared to expression of GSK3 $\beta$ (S9A) and tau (Figure 4).
Since GSK3 $\beta$ phosphorylates many substrates, results need to be interpreted with some caution. However, our results suggest that GSK3 $\beta$ or another kinase induces formation of hyperphosphorylated tau species. Model Hirano bodies could potentiate cell death by increasing the local concentration of tau through F-actin binding, serving as the nucleation agent in subsequent tau phosphorylation and aggregation. G272V and P301L have a higher propensity to aggregate than $441 \mathrm{WT}$ (see below [47]), and may therefore aggregate and induce cell death more easily in the presence of Hirano bodies. G272V and P301L were more phosphorylated in the presence of model Hirano bodies (Figure 6), lending credence to this supposition. Further experiments show that expression of dominant negative GSK3 $\beta$ (K85A) in the presence AICD and tau decreases levels of cell death to that expected from an additive effect of cell death induced by $\mathrm{AICD}+$ tau alone (Figure 2, Table 1). However, model Hirano bodies did not further enhance cell death in the presence of R406W shown previously to be hypophosphorylated in the presence of GSK3 $\beta[7,58]$ or tau mutants that did not contain the majority of GSK3 $\beta$ phosphorylation sites (K18 and K18 $\Delta \mathrm{K} 280$ ). Expression of dominant negative GSK3 $\beta$ (K85A) in the presence of G272V and model Hirano bodies lowered cell death to that expected of an additive effect of cell death induced by G272V + model Hirano bodies alone (Figure 5). This may suggest a complementary role for phosphorylation and aggregation.

Consistent with this, in vitro studies characterizing the 352PHP tau mutant show that these mutations collectively inhibit aggregation compared to WT tau [84]. Therefore, transient phosphorylation and dephosphorylation of tau may be critical to formation of a pathologically relevant tau species. This may explain why expression of 352PHP tau and model Hirano bodies does not cause increased cell death in our system. It has been shown that phosphorylation of specific residues on tau is required to prime tau for additional phosphorylation [85-88], and that 352PHP becomes phosphorylated in cell cultures under certain conditions at other serine/threonine residues that are not mutated [89]. Therefore, the amino acid charge substitutions used to create the phosphorylation mimics on 352PHP may prime phosphorylation at other sites. This could explain why expression of either AICD or GSK3 $\beta$ with 352PHP results in a synergistic cell death phenotype. These results support the hypothesis that model Hirano bodies enhance cell death in the presence of highly phosphorylated tau, and reduce cell death in the presence of other tau variants.

\section{Aggregation of FTDP-17 mutant tau}

The ability of tau to promote cell death in the presence of model Hirano bodies and/or AICD correlates most 
strongly with the propensity of tau to self-aggregate. Multiple studies show that FTDP-17 tau mutants vary widely in their ability to form PHFs and NFTs in vitro, in cell culture, and in vivo as well as the kinetics in which they form [90]. Studies with recombinant tau obtained from bacteria showed that $\Delta \mathrm{K} 280(441 \mathrm{tau})$ had a greater propensity to form paired helical filaments than P301L > G272V > R406W > 441WT with a faster kinetic speed [47]. Tau mutants P301L and K18 $\Delta$ K280 show the greatest tendency to aggregate [47], and potentiated the highest levels of cell death in the presence of model Hirano bodies. All tau mutants except for K18 $\Delta 280$ were incapable of inducing cell death alone consistent with previous reports [50,54]. The ability of $\mathrm{K} 18 \Delta \mathrm{K} 280$ to cause cell death was attributed to the ability of this fragment to aggregate since mutation of hexapeptide motifs in tau essential for $\beta$-structure and aggregation reduced cell death and rescued neurodegeneration [55,91]. Model Hirano bodies have no effect on cell death initiated by expression of exogenous $\mathrm{K} 18 \Delta \mathrm{K} 280$. Because this mutant is capable of initiating cell death on its own, it likely does not need model Hirano bodies to further aid its aggregation. Although little is known about the $\mathrm{R} 5 \mathrm{H}$ tau mutation, R5L has been characterized in vitro with increased nucleation rate of aggregation and increased numbers of tau filaments [92], a trait shared with R5H [18]. R406W tau does not robustly aggregate in vitro or in cell cultures [92-95]. In fact, R406W tau has been shown to be hypophosphorylated in resting cells compared to WT tau $[93,95]$, and hypophosphorylated when exposed to GSK3 $\beta$ in vitro [94]. Thus, tau phosphorylation may be related to tau aggregation and cell death. The specific tau species responsible for potentiating cell death in our model is unknown, and more studies are needed to determine whether further tau modification and proteolytic processing contributes to cell death. In support of a relationship between aggregation and cell death, some FTDP-17 patients exhibit more aggressive symptoms than $A D$ patients, coincident with robust tau pathology at an earlier age of onset (for review, see [96]).

A possible mechanism for the interaction of model Hirano bodies and tau is that model Hirano bodies increase the local concentration of tau through a direct or indirect interaction. All the full-length tau proteins bound F-actin in our study and all tau proteins with the exception of 352PHP were enriched with model Hirano bodies (Figures 3 and 7). While tau binds with a lower affinity to actin than microtubules, the concentration of F-actin in a Hirano body could be $360-600 \mu \mathrm{M}$ based on the actin concentration in F-actin solutions bundled by the Dictyostelium $34 \mathrm{kDa}$ actin bundling protein [97]. The high local concentration of F-actin in a model Hirano body could compensate for weak tau binding. Phosphorylation, aggregation, or other protein modifications could become more favorable due to the high local concentration. Tau mutants most prone to aggregation then initiate cell death. Previous studies with recombinant tau induced to aggregate by the presence of heparin showed that both P301L and G272V aggregated faster and to a greater extent than R406W or 441WT [47]. The truncated K18 $\Delta$ K280 aggregated exceptionally quickly in contrast to K18. Model Hirano bodies were not able to protect against cell death in the presence of these aggregation-prone tau mutants alone or in addition to AICD. In contrast, WT tau isoforms and tau mutants $\mathrm{R} 406 \mathrm{~W}$ and $\mathrm{R} 5 \mathrm{H}$ did not cause cell death in the presence of model Hirano bodies, and model Hirano bodies were able to protect from cell death induced by these tau mutants in the presence of AICD. These forms of tau were slower to aggregate and did so to a smaller extent than P301L, G272V, or K18 1 K280 [47].

\section{AICD and tau}

Our data is consistent with the idea that tau significantly contributes to cell death in the presence of AICD. This complements previous results showing that expression of exogenous c31/APP/352PHP tau or AICD/352PHP tau results in a potentiation of cell death compared to cells expressing AICD or 352PHP alone [44]. In this study, expression of all tau forms tested enhanced cell death in the presence of AICD (albeit at different levels) to a level that was significantly greater than the sum of AICD and tau expressed separately with the exception of $352 \mathrm{WT}, 441 \mathrm{WT}$, and $\mathrm{K} 18 \Delta \mathrm{K} 280$ (Table 1). It is noteworthy that exogenous expression of dominant negative GSK3 $\beta$ (K85A) with AICD and all forms of tau that previously induced synergistic cell death decreased to an additive sum of AICD alone plus tau alone, while AICD and all forms of tau that do not induce synergistic cell death were unaffected by GSK3 $\beta$ (K85A). In addition, the presence of model Hirano bodies with AICD and tau decreased the amount of GSK3 $\beta$. These results support a model in which AICD potentiates cell death in the presence of tau and that phosphorylation of tau is important to that process. AICD has been shown to up-regulate or be upstream of GSK3 $\beta$ activation [7]. Our results strongly support the conclusion that the interplay between AICD and tau involves activation of GSK3 $\beta$ and phosphorylation of tau, and that there are at least two major effects of AICD. AICD alone activates Fe65, Tip60, and caspases, while the interaction of AICD with tau to cause cell death requires activation of GSK3 $\beta$.

\section{Conclusion}

We provide further evidence that Hirano bodies have a specific effect on the pathogenesis of neurodegenerative disease, with respect to tau and C-terminal fragments of APP. We suggest that Hirano bodies do not serve a 
general protective function by simply accumulating cytosolic proteins, but rather protect against cell death initiated by AICD and mitigate or enhance cell death dependent on the biochemical properties of tau. This data complements key discoveries made in transgenic animal models and neuronal cell culture reporting abnormal rearrangement of $\mathrm{F}$-actin during cell stress or neurodegeneration, and suggest that Hirano bodies play a complex role in the pathogenesis of disease.

\section{Methods}

\section{Plasmids}

CT-EGFP was utilized to induce model Hirano bodies as previously described $[42,44]$. Other plasmids utilized encoded GFP (pEGFP-N1, Clontech, Mountain View, CA), AICD (APPc58-myc, c-terminal 58 amino acids of APP-695, a generous gift from Bradley Hyman, Harvard Medical School) [98], and HA-tagged GSK3 $\beta$ (Addgene plasmid 15994) [99]. GSK3 $\beta$ (S9A) (constitutively active) [100], and GSK3 $\beta$ (K85A) (dominant negative) $[7,59]$ were constructed from HA-GSK3 $\beta$ using a QuikChange II XL Site-Directed Mutagenesis Kit (Stratagene, La Jolla CA) using mutagenic primers K85A 5'GAACTGGTCGC CATCAAGAAAGTATTGCAGGAC 3' and S9A 5' CCA GAACCACCGCCTTTGCGGAGAGC 3'. The coding sequences of these plasmids were confirmed by sequencing.

A single MAPT gene in the central nervous system generates six tau isoforms by alternative splicing of its pre-mRNA. Isoforms ranging in size from 352-441 residues differ by exclusion or inclusion of exons 2,3, and 10. Plasmids were constructed to express wild type tau (352WT or 441WT) or mutant forms (352PHP, R5H, G272V, P301L, R406W, K18, or K18 K280) in either mammalian or bacterial cells. 352PHP is a tau mutant created in the shortest tau isoform (352WT) in which 10 serine/threonine residues (S198, S199, S202, T231, S235, S396, S404, S409, S413, and S422) were mutated to glutamic acid to mimic a hyperphosphorylated state (generous gifts from Roland Brandt, University of Osnabrück, Osnabrück, Germany) [101] as shown in Figure 1. K18 comprises the microtubule-binding domain (amino acids Q244 to E372, numbering from the 441 length tau) [47]. To generate N-terminal FLAG-tagged tau constructs with a CMV promoter for expression in mammalian cells (Figure 1), the coding sequence of 352PHP was digested from the 352PHP plasmid with ClaI. Using the coding sequence of 441 length human WT tau (441WT) in pET-29b (Addgene plasmid 16316) [102] as a template, ClaI restriction sites were introduced through PCR, and 441WT coding sequence was cloned into the ClaI site of the remainder of the 352PHP plasmid backbone containing the FLAG-tag and CMV promoter. Tau mutants in the 441 length tau in either the mammalian or bacterial expression plasmids were constructed using a QuikChange
II XL Site-Directed Mutagenesis Kit (Stratagene, La Jolla CA). Primers for mutagenesis were: $\triangle K 280$ (deletion of K280) 5' GCAGATAATTAATAAGCTGGATCTTAGC, R5H 5'ATGGCTGAGCCCCACCAGGAGTTCGAAG, G272V 5'GCACCAGCCGGGAGTCGGGAAGGTGCAG, P301L 5'ATCAACACGTCCTGGGAGGCGGCAG, and R406W 5'GGACACGTCTCCATGGCATCTCAGCAA TG. Tau constructs $\mathrm{K} 18$ and $\mathrm{K} 18 \Delta \mathrm{K} 280$ were generated by the introduction of ClaI sites to the 5' and 3' end of $\mathrm{K} 18$ or $\mathrm{K} 18 \Delta \mathrm{K} 280$ using either the $441 \mathrm{WT}$ or $\Delta \mathrm{K} 280441 \mathrm{WT}$ as template, digesting the PCR products, and ligating into the ClaI site of the remainder of the 352PHP plasmid backbone after deletion of the coding sequence. The coding sequences of all plasmids were verified by sequencing.

\section{Immunofluorescence}

Hirano bodies have been proposed to have a glial origin [103], and because glial cells have been shown to be important mediators of cell death induced by $\mathrm{A} \beta$ and tau [104], H4 human astroglioma cells were utilized. Furthermore, $\mathrm{H} 4$ cells have been shown to contain nearly undetectable levels of endogenous tau [105,106]. H4 astroglioma cells (American Type Culture Collection, Manassas, VA) were cultured in Dulbecco's Modified Eagle Medium (DMEM) supplemented with 10\% fetal bovine serum (Atlanta Biologicals, Flowery Branch, GA) at $37^{\circ} \mathrm{C}$ and $5 \% \mathrm{CO}_{2} . \mathrm{H} 4$ cells were plated onto glass coverslips and allowed to adhere for $24 \mathrm{~h}$. Cells were transiently transfected with equal amounts of plasmid $(1 \mu \mathrm{g}$ each) using Lipofectamine LTX (Invitrogen, Carlsbad, CA) according to manufacturer's instructions. Cells were processed after $24 \mathrm{~h}$ for immunofluorescence as previously described [42]. Coverslips were visualized with a Zeiss Axioobserver Z1 equipped with an AxioCam MRm controlled by AxioVision4.6 software. Antibodies used were anti-FLAG rabbit antibody to label tau (Sigma-Aldrich, St. Louis, MO), and Alexa Fluor 350 conjugated anti-rabbit secondary antibody (Molecular Probes, Eugene, OR). F-actin was visualized using TRITC-conjugated phalloidin (Sigma-Aldrich, St. Louis, $\mathrm{MO}$ ), and nuclei were stained with DAPI (Sigma-Aldrich, St. Louis, MO). Characterization of the types of actin-rich structures was performed on $\mathrm{H} 4$ cells transfected as described above and processed for immunofluorescence $48 \mathrm{~h}$ after transfection. CT-GFP-rich structures were characterized having normal cellular localization, fibrillar structures, Hirano bodies or large Hirano bodies. Hirano body size was determined using NIH ImageJ using the threshold function to eliminate user bias. Large Hirano bodies are those in the fourth quartile. Significance between samples was determined using the non-parametric Mann-Whitney test. Experiments were performed in a minimum of triplicate. 


\section{Immunohistochemistry}

All samples were de-identified and coded only by sample number (see Table 4), and supplied as eight-micron, paraformaldehyde-fixed paraffin sections mounted on slides. Mounted sections were dewaxed in xylene and rehydrated in an ethanol gradient prior to antigen retrieval in boiling $10 \mathrm{mM}$ sodium citrate plus $0.05 \%$ Tween 20 pH 6.0 for 20 minutes. Endogenous peroxidase activity was inhibited by incubating sections in 3\% hydrogen peroxide for 10 minutes prior to washing with phosphate buffered saline (PBS) and blocking with $10 \mathrm{mg} / \mathrm{ml}$ bovine serum albumin in PBS overnight. Samples were stained for total tau using mouse tau 5 antibody (1/400 in PBS, 4\% BSA) (Santa Cruz Biotechnology, Dallas, TX), or tau phosphorylated at serine 199/202 using rabbit antipTau199/202 (1/300 in PBS, 4\% BSA) (Sigma-Aldrich Chemical Co, St. Louis, MO). Anti-mouse and anti-rabbit biotinylated secondary antibodies (1/800 in PBS) (SigmaAldrich Chemical Co, St. Louis, MO) followed by a streptavidin-HRP polymer complex (1/1000 in PBS) with diaminobenzidine enhanced substrate system (Vector Laboratory, Burlingame, CA) were utilized as a detection system. Samples were counterstained with hematoxylin/ eosin (Sigma-Aldrich Chemical Co, St. Louis, MO) to visualize Hirano bodies. All protocols were approved by the University of Georgia Institutional Biosafety Committee and the Institutional Review Board.

\section{Cell death assays}

24 hours prior to transfection, 8,000 H4 cells/well were plated into 96-well plates (Nalge Nunc, Rochester, NY). Cells were transiently transfected with equal amounts of plasmid (250 ng each) using Lipofectamine LTX (Invitrogen, Carlsbad, CA) according to manufacturer's instructions. In some experiments, the amount of GSK3 $\beta$ (S9A) plasmid was reduced (150 ng) to examine its dose dependent effect while the amounts of the other plasmids were kept constant. 24 hours post-transfection, cell death assays were performed as previously described [44]. Briefly, cells were incubated with 9 nM Sytox Orange, a

Table 4 Samples of human hippocampus were obtained from the Alzheimer's Disease Research Center at Emory University

\begin{tabular}{lll}
\hline Case number & Age at death & Race/sex \\
\hline AD-1 & 81 & Male \\
AD-2 & 83 & Caucasian male \\
AD-3 & 66 & African American female \\
Control-1 & 88 & Caucasian female \\
Control-2 & 94 & Caucasian male
\end{tabular}

Samples were screened for presence of Hirano bodies, and were derived from patients with $A D$, or control subjects that had no known history of neurological disease and no neuropathological changes indicative of neurodegenerative disease at autopsy. cell impermeable nucleic acid dye (Invitrogen, Carlsbad, $\mathrm{CA}$ ), and $264 \mu \mathrm{M}$ Hoechst 33258 (Sigma-Aldrich Chemical Co, St. Louis, MO) for $15 \mathrm{~min}$ at $37^{\circ} \mathrm{C}$ and $5 \%$ $\mathrm{CO}_{2}$. Due to inefficient transfection, GFP was used as a transfection control. Sytox Orange positive fluorescence was used to indicate dead cells. A minimum of 80 cells was counted per sample and each condition was sampled at least three independent times. Analysis of statistical significance was performed using Student's t-test. The interactions of multiple components and their contributions to cell death were analyzed by using propagation of error, comparing the calculated sum and standard deviations of cell death observed when the two components were separate to that observed when they were present in the assay together to determine the error of the calculated sum. This strategy and applying Student's t-test allowed determination of whether the cell death observed when the two components were present together was significantly greater than expected, suggesting a biological and/ or molecular interaction.

\section{Protein purification}

Expression of wild type and mutated forms of tau in pET29-b was induced by the addition of $1 \mathrm{mM}$ IPTG in E.coli Bl-21(DE-3) with the exception of 352PHP which required no IPTG. Recombinant tau proteins were purified as previously described [107] with the following modifications. Cells were lysed by the addition of $0.2 \mathrm{mg} / \mathrm{ml}$ of lysozyme in the bacterial resuspension buffer and stirred until lysis was complete. The lysate was sonicated prior to the addition of $\mathrm{NaCl}$ and subsequent boiling. The lysate was clarified by ultracentrifugation and the supernatant was diluted with cation exchange buffer $\mathrm{A}$ without $\mathrm{NaCl}$ to a final concentration of $50 \mathrm{mM} \mathrm{NaCl}$, and applied to CM-cellulose column (GE Healthcare Life Sciences, Piscataway, NJ). The column was washed with cation exchange buffer A until the OD reached baseline levels and subsequently eluted with a linear gradient $0.05-0.4$ $\mathrm{M} \mathrm{NaCl}$ gradient. Fractions containing tau were identified by SDS-PAGE, collected, diluted with cation exchange buffer $\mathrm{A}$ without $\mathrm{NaCl}$ to a final concentration of $50 \mathrm{mM} \mathrm{NaCl}$ and concentrated on CM-cellulose. The mutant tau was eluted with cation exchange buffer with $0.6 \mathrm{M} \mathrm{NaCl}$. Fractions containing the mutant tau were identified by OD280 $\mathrm{nm}$, sedimented at $13,000 \times \mathrm{g}$ for $15 \mathrm{~min}$ at $4^{\circ} \mathrm{C}$, and the supernatant applied directly to sephacryl S-200 (GE Healthcare Life Sciences, Piscataway, NJ) column equilibrated with $10 \mathrm{mM}$ HEPES, pH 7.4, $150 \mathrm{mM} \mathrm{NaCl}, 1 \mathrm{mM}$ DTT, and $0.02 \%$ sodium azide. Fractions containing tau were identified by SDS-PAGE. Individual fractions containing the highest concentrations of tau were frozen at $-80^{\circ} \mathrm{C}$ and used without further concentrating. Five hours prior to use, the tau was dialyzed versus cosedimentation buffer (see below). 
Actin was prepared from rabbit skeletal muscle acetone powder $[108,109]$ and further purified by application to sephadex G-150. The actin was maintained for up to 1 week in cosedimentation buffer (10 mM PIPES, pH 7.0, $100 \mathrm{mM} \mathrm{KCl}, 1 \mathrm{mM} \mathrm{MgCl}$, $1 \mathrm{mM}$ ATP, $1 \mathrm{mM}$ DTT, and $0.02 \%$ sodium azide) with daily buffer changes. The protein concentrations of actin and tau were determined using bicinchoninic acid method (Pierce Protein Biology, Rockford, IL) [110] with bovine serum albumin as a standard.

Cosedimentation assays were performed as previously described [111]. F-actin and/or tau mixtures were incubated $2 \mathrm{~h}$ prior to ultracentrifugation. The samples were analyzed by SDS-PAGE and quantified utilizing ChemiDoc $^{\text {TM }}$ MP System and Image Lab ${ }^{\mathrm{TM}}$ software (BioRad Laboratories, Hercules, CA). The amount of tau in the pellets was corrected for the small amount of tau alone found in the pellet. Experiments were performed in a minimum of triplicate.

\section{Western blot}

HEK293T cells (American Type Culture Collection, Manassas, VA) were cultured in Dulbecco's Modified Eagle Medium (DMEM) supplemented with 10\% fetal bovine serum (Atlanta Biologicals, Flowery Branch, $\mathrm{GA})$ at $37^{\circ} \mathrm{C}$ and $5 \% \mathrm{CO}_{2}$. They were plated at a density of $4 \times 10^{5}$ cells per $60 \mathrm{~mm}$ diameter dish. Cells were transfected with equal amounts of plasmid ( $2.5 \mu \mathrm{g}$ each) using Lipofectamine 2000 (Invitrogen, Carlsbad, CA) according to manufacturer's instructions. At 48 hours after transfection, cells were washed twice with ice-cold PBS and lysed with $20 \mathrm{mM}$ Tris, $\mathrm{pH} 7.5,1 \%$ triton-X100, $0.1 \%$ SDS, $0.5 \%$ deoxycholic acid, and 10\% glycerol with $10 \mu \mathrm{L}$ protease inhibitor cocktail (5 mM EGTA, $1 \mathrm{mM}$ DTT, $100 \mathrm{mM}$ leupeptin, $10 \mathrm{mM}$ pepstatin, 0.1 M PMSF, $0.1 \mathrm{M}$ benzamidine, and $0.5 \mathrm{M} \varepsilon$-aminocaproic acid). Cell debris was separated from total homogenate by centrifugation at $13,000 \mathrm{~g}$ for $15 \mathrm{~min}$ at $4^{\circ} \mathrm{C}$. The supernatant was stored at $-80^{\circ} \mathrm{C}$ until used. Protein concentrations of the supernatants were determined by bicinchoninic acid assay using BSA as a standard [110]. For western blot analysis, samples were loaded at equal total protein, separated by SDS-PAGE, and transferred to nitrocellulose membranes. Blots were blocked in 5\% nonfat dry milk in TBST and probed using with either rabbit anti-pTau199/202 (1/4500) (Sigma-Aldrich Chemical Co, St. Louis, MO), rabbit-anti pTau231 (1/2000) (Acris Antibodies, San Diego, CA), goat-anti pTau396 (1/2000) (Santa Cruz Biotechnology, Dallas, TX), rabbit anti-GFP (1/5000) (Sigma-Aldrich Chemical Co., St. Louis, MO), mouse antitau5 (1/5000) (Santa Cruz Biotechnology, Dallas, TX), mouse anti-alpha tubulin (1/8000) (Millipore, Billerica, MA), mouse anti-myc (1/8000) (Cell Signaling Technology, Danvers, MA), or rabbit anti-GSK-3 $\beta$ (1/1000) (Santa
Cruz Biotechnology, Dallas, TX). After three washes with TBST, blots were incubated with either goat anti-mouse horseradish peroxidase, goat anti-rabbit horseradish peroxidase (1/10000) (Pierce-lab, Rockford, IL), or donkey anti-goat horseradish peroxidase (1/8000) (Millipore, Billerica, MA) and detected by chemiluminescence using SuperSignal Western Dura Extended Duration Substrate (Thermo Scientific, Rockford IL). Images were captured utilizing ChemiDoc ${ }^{\mathrm{TM}} \mathrm{MP}$ system and Image $\mathrm{Lab}^{\mathrm{TM}}$ software (Bio-Rad Laboratories, Hercules, CA).

Blots were performed in duplicate.

\section{Additional file}

Additional file 1: Figure S1. Mutant tau does not affect model Hirano body formation. $\mathrm{H} 4$ cells were transiently transfected with equal amounts of plasmid DNA encoding CT-GFP to induce model Hirano bodies in the absence (white bars) or presence of either 352WT (stripe bar), 441WT (grey bar), 352 PHP (black bar), or P301L (crosshatch bar). Cells were fixed after 48 hrs. Model Hirano bodies were characterized as normal, fibrillar, Hirano body, or large Hirano body as determined by GFP fluorescence. There is no difference between the populations of cells. Scale bar $=20 \mu \mathrm{m}$.

\section{Competing interests}

The authors declare that they have no competing interests.

\section{Authors' contributions}

All authors in this manuscript contributed to the design of the study, analysis/ interpretation of data, and drafting of this manuscript. WS, MFurgerson, JMS, PE, and RF carried out all experiments under the supervision of MFechheimer and RF. WS and MFurgerson performed the cell death assays and mutagenesis. WS and JMS performed the immunofluorescence staining. MFurgerson and PE performed the immunohistochemistry staining. RF performed the protein purification and F-actin cosedimentation assay. MG sectioned and supplied human brain tissue samples. All authors have read and approved this manuscript for publication.

\section{Acknowledgements}

We would like to thank Drs. Stephen Hajduk and Richard Meagher for use of their microscopes. This work was supported by NIH (1R01-NS04645101) (R.F. and M.Fechheimer) and by National Institute of Aging Emory Alzheimer's Disease Research Center P50 AG025688 (M.G.).

\section{Author details}

'Department of Cellular Biology, University of Georgia, Athens, GA 30602, USA. ${ }^{2}$ Department of Biochemistry and Molecular Biology, University of Georgia, Athens, GA 30602, USA. ${ }^{3}$ Pathology and Laboratory Medicine, Emory University School of Medicine, Atlanta, GA 30322, USA.

Received: 7 April 2014 Accepted: 6 June 2014

Published: 14 June 2014

\section{References}

1. Huang $Y$, Mucke L: Alzheimer mechanisms and therapeutic strategies. Cell 2012, 148:1204-1222.

2. Sherrington R, Rogaev El, Liang Y, Rogaeva EA, Levesque G, Ikeda M, Chi H, Lin C, Li G, Holman K, Tsuda T, Mar L, Foncin JF, Bruni AC, Montesi MP, Sorbi S, Rainero I, Pinessi L, Nee L, Chumakov I, Pollen D, Brookes A, Sanseau P, Polinsky RJ, Wasco W, Da Silva HA, Haines JL, Perkicak-Vance MA, Tanzi RE, Roses $A D$, et al: Cloning of a gene bearing missense mutations in early-onset familial Alzheimer's disease. Nature 1995, 375:754-760.

3. Levy-Lahad E, Wasco W, Poorkaj P, Romano DM, Oshima J, Pettingell WH, Yu CE, Jondro PD, Schmidt SD, Wang K, Crowley A, Fu Y-H, Guenette SY, Galas D, Nemens E, Wijsman EM, Bird TD, Schellenberg G, Tanzi R: 
Candidate gene for the chromosome 1 familial Alzheimer's disease locus. Science 1995, 269:973-977.

4. Hardy J, Selkoe DJ: The amyloid hypothesis of Alzheimer's disease: Progress and problems on the road to therapeutics. Science 2002, 297:353-356.

5. Beckett C, Nalivaeva NN, Turner AJ: Nuclear signalling by membrane protein intracellular domains: the AICD enigma. Cell Signal 2012, 24:402-409.

6. Pardossi-Piquard R, Checler F: The physiology of the beta-amyloid precursor protein intracellular domain AICD. J Neurochem 2012, 120(Suppl 1):109-124.

7. Kim H-S, Kim E-M, Lee J-P, Park CH, Kim S, Seo J-H, Chang K-A, Yu E, Jeong S-J, Chong $\mathrm{YH}$, Suh AY-H: C-terminal fragments of amyloid precursor protein exert neurotoxicity by inducing glycogen synthase kinase-3 $\beta$ expression. FASEB J 2003, 17:1951-1954.

8. Von Rotz RC, Kohli BM, Bosset J, Meier M, Suzuki T, Nitsch RM, Konietzko U: The APP intracellular domain forms nuclear multiprotein complexes and regulates the transcription of its own precursor. J Cell Sci 2004, 117:4435-4448.

9. Ghosal K, Vogt DL, Liang M, Shen Y, Lamb BT, Pimplikar SW: Alzheimer's disease-like pathological features in transgenic mice expressing the APP intracellular domain. Proc Natl Acad Sci U S A 2009, 106:18367-18372.

10. Braak E, Braak H, Mandelkow EM: A sequence of cytoskeleton changes related to the formation of neurofibrillary tangles and neuropil threads. Acta Neuropathol 1994, 87:554-567.

11. Braak H, Braak E: Neuropathological stageing of Alzheimer-related changes. Acta Neuropathol 1991, 82:239-259.

12. Holzer M, Holzapfel HP, Zedlick D, Bruckner MK, Arendt T: Abnormally phosphorylated tau protein in Alzheimer's disease: heterogeneity of individual regional distribution and relationship to clinical severity. Neuroscience 1994, 63:499-516.

13. Hutton M, Lendon CL, Rizzu P, Baker M, Froelich S, Houlden H, PickeringBrown S, Chakraverty S, Isaacs A, Grover A, Hackett J, Adamson J, Lincoln S, Dickson D, Davies P, Petersen RC, Stevens M, de Graaff E, Wauters E, van Baren J, Hillebrand M, Joosse M, Kwon JM, Nowotny P, Che LK, Norton J, Morris JC, Reed LA, Trojanowski J, Basun H, et al: Association of missense and 5'-splice-site mutations in tau with the inherited dementia FTDP-17. Nature 1998, 393:702-705.

14. Lee VM, Goedert M, Trojanowski JQ: Neurodegenerative tauopathies. Ann Rev Neurosci 2001, 24:1121-1159.

15. van Swieten JC, Stevens M, Rosso SM, Rizzu P, Joosse M, de Koning I, Kamphorst W, Ravid R, Spillantini MG, Niermeijer MF, Heutink P: Phenotypic variation in hereditary frontotemporal dementia with tau mutations. Ann Neurol 1999, 46:617-626

16. Mirra SS, Murrell JR, Gearing M, Spillantini MG, Goedert M, Crowther RA, Levey Al, Jones R, Green J, Shoffner JM, Wainer BH, Schmidt ML, Trojanowski JQ, Ghetti B: Tau pathology in a family with dementia and a P301L mutation in tau. J Neuropathol Exp Neurol 1999, 58:335-345.

17. Miyasaka T, Morishima-Kawashima M, Ravid R, Kamphorst W, Nagashima K, Ihara Y: Selective deposition of mutant tau in the FTDP-17 brain affected by the P301L mutation. J Neuropathol Exp Neurol 2001, 60:872-884.

18. Hayashi S, Toyoshima Y, Hasegawa M, Umeda Y, Wakabayashi K, Tokiguchi $\mathrm{S}$, Iwatsubo T, Takahashi $\mathrm{H}$ : Late-onset frontotemporal dementia with a novel exon 1 (Arg5His) tau gene mutation. Ann Neurol 2002, 51:525-530.

19. Momeni P, Pittman A, Lashley T, Vandrovcova J, Malzer E, Luk C, Hulette C, Lees A, Revesz T, Hardy J, De Silva R: Clinical and pathological features of an Alzheimer's disease patient with the MAPT Delta K280 mutation. Neurobiol Aging 2009, 30:388-393.

20. Gibson PH, Tomlinson BE: Numbers of Hirano bodies in the hippocampus of normal and demented people with Alzheimer's disease. J Neurol SCi 1977, 33:199-206.

21. Hirano A: Hirano bodies and related neuronal inclusions. Neuropathol Appl Neurobiol 1994, 20:3-11.

22. Martinez-Saez E, Gelpi E, Rey M, Ferrer I, Ribalta T, Botta-Orfila T, Nos C, Yague J, Sanchez-Valle R: Hirano body-rich subtypes of Creutzfeldt-Jakob disease. Neuropathol Appl Neurobiol 2011, 38:153-161.

23. Minamide LS, Striegl AM, Boyle JA, Meberg PJ, Bamburg JR: Neurodegenerative stimuli induce persistent ADF/Cofilin-actin rods that disrupt distal neurite function. Nat Cell Biol 2000, 2:628-636.

24. Fulga TA, Elson-Schwab I, Khurana V, Steinhib ML, Spires TL, Hyman BT, Feany MB: Abnormal bundling and accumulation of F-actin mediates tau-induced neuronal degeneration in vivo. Nat Cell Biol 2007, 9:139-148.
25. Whiteman IT, Minamide LS, Goh De L, Bamburg JR, Goldsbury C: Rapid changes in phospho-MAP/tau epitopes during neuronal stress: cofilin-actin rods primarily recruit microtubule binding domain epitopes. PLoS One 2011, 6:e20878.

26. Correas I, Padilla R, Avila J: The tubulin-binding sequence of brain microtubule-associated proteins, tau and MAP-2, is also involved in actin binding. Biochem J 1990, 269:61-64.

27. Roger B, Al-Bassam J, Dehmelt L, Milligan RA, Halpain S: MAP2c, but not tau, binds and bundles F-actin via its microtubule binding domain. Curr Biol 2004, 14:363-371.

28. He HJ, Wang XS, Pan R, Wang DL, Liu MN, He RQ: The proline-rich domain of tau plays a role in interactions with actin. BMC Cell Biol 2009, 10:81.

29. Goldman JE: The association of actin with Hirano bodies. J Neuropathol Exp Neurol 1983, 42:146-152.

30. Galloway PG, Perry G, Gambetti P: Hirano body filaments contain actin and actin-associated proteins. J Neuropathol Exp Neurol 1987, 46:185-199.

31. Maciver SK, Harrington CR: Two actin binding proteins, actin depolymerizing factor and cofilin, are associated with Hirano bodies. Neuroreport 1995, 6:1985-1988.

32. Galloway PG, Perry G, Kosik KS, Gambetti P: Hirano bodies contain tau protein. Brain Res 1987, 403:337-340.

33. Peterson C, Kress Y, Vallee R, Goldman JE: High molecular weight microtubule-associated proteins bind to actin lattices (Hirano bodies). Acta Neuropathol 1988, 77:168-174.

34. Jordan-Sciutto K, Dragich J, Walcott D, Bowser R: The presence of FAC1 protein in Hirano bodies. Neuropathol Appl Neurobiol 1998, 24:359-366.

35. Peress NS, Perillo E: Differential expression of TFG Beta 1, 2, and 3 isotypes in Alzheimer's disease: a comparative immunohistochemical study with cerebral infarction, aged human and mouse control brains. J Neuropathol Exp Neurol 1995, 54:802-811.

36. Munoz DG, Wang D, Greenberg BD: Hirano bodies accumulate C-terminal sequences of beta-amyloid precursor protein (beta-APP) epitopes. J Neuropathol Exp Neurol 1993, 52:14-21.

37. Ha S, Furukawa R, Fechheimer M: Association of AICD and Fe65 with Hirano bodies reduces transcriptional activation and initiation of apoptosis. Neurobiol Aging 2011, 32:2287-2298.

38. Hirano A, Dembitzer HM, Kurland LT, Zimmerman HM: The fine structure of some intraganlionic alterations. J Neuropathol Exp Neurol 1968, 27:167-182.

39. Lim RWL, Furukawa R, Fechheimer M: Evidence of intramolecular regulation of the Dictyostelium discoideum 34,000 dalton F-actin bundling protein. Biochemistry 1999, 38:16323-16332.

40. Maselli AG, Davis R, Furukawa R, Fechheimer M: Formation of Hirano bodies in Dictyostelium and mammalian cells induced by expression of a modified form of an actin cross-linking protein. J Cell Sci 2002, 115:1939-1952.

41. Maselli AG, Furukawa R, Thomson SAM, Davis RC, Fechheimer M: Formation of Hirano bodies induced by expression of an actin cross-linking protein with a gain of function mutation. Eucaryot Cell 2003, 2:778-787.

42. Davis RC, Furukawa R, Fechheimer M: A cell culture model for investigation of Hirano bodies. Acta Neuropathol 2008, 115:205-217.

43. Ha S, Furukawa R, Stramiello M, Wagner JJ, Fechheimer M: Transgenic mouse model for the formation of Hirano bodies. BMC Neurosci 2011, 12:97-113.

44. Furgerson $M$, Fechheimer $M$, Furukawa R: Model Hirano bodies protect against tau-independent and tau-dependent cell death initiated by the amyloid precursor protein intracellular domain. PLoS One 2012, 7:e44996.

45. Ittner LM, Gotz J: Amyloid-beta and tau-a toxic pas de deux in Alzheimer's disease. Nat Rev Neurosci 2011, 12:65-72.

46. Hoover BR, Reed MN, Su J, Penrod RD, Kotilinek LA, Grant MK, Pitstick R, Carlson GA, Lanier LM, Yuan LL, Ashe KH, Liao D: Tau mislocalization to dendritic spines mediates synaptic dysfunction independently of neurodegeneration. Neuron 2010, 68:1067-1081.

47. Barghorn S, Zheng-Fischhofer Q, Ackmann M, Biernat J, Von Bergen M, Mandelkow EM, Mandelkow E: Structure, microtubule interactions, and paired helical filament aggregation by tau mutants of frontotemporal dementias. Biochemistry 2000, 39:11714-11721.

48. Von Bergen M, Barghorn S, Li L, Marx A, Biernat J, Mandelkow EM, Mandelkow E: Mutations of tau protein in frontotemporal dementia promote aggregation of paired helical filaments by enhancing local beta-structure. J Biol Chem 2001, 276:48165-48174. 
49. Goedert M, Jakes R, Crowther RA: Effects of frontotemporal dementia FTDP-17 mutations on heparin-induced assembly of tau filaments. FEBS Lett 1999, 450:306-311.

50. Wang YP, Biernat J, Pickhardt M, Mandelkow E, Mandelkow EM: Stepwise proteolysis liberates tau fragments that nucleate the Alzheimer-like aggregation of full-length tau in a neuronal cell model. Proc Natl Acad Sci US A 2007, 104:10252-10257.

51. Eckermann K, Mocanu MM, Khlistunova I, Biernat J, Nissen A, Hofmann A Schonig K, Bujard H, Haemisch A, Mandelkow E, Zhou L, Rune G, Mandelkow EM: The beta-propensity of Tau determines aggregation and synaptic loss in inducible mouse models of tauopathy. J Biol Chem 2007, 282:31755-31765.

52. Mocanu MM, Nissen A, Eckermann K, Khlistunova I, Biernat J, Drexler D, Petrova O, Schonig K, Bujard H, Mandelkow E, Zhou L, Rune G, Mandelkow EM: The potential for beta-structure in the repeat domain of tau protein determines aggregation, synaptic decay, neuronal loss, and coassembly with endogenous Tau in inducible mouse models of tauopathy. J Neurosci 2008, 16:737-748.

53. Fatouros C, Pir GJ, Biernat J, Koushika SP, Mandelkow E, Mandelkow EM, Schmidt E, Baumeister R: Inhibition of tau aggregation in a novel Caenorhabditis elegans model of tauopathy mitigates proteotoxicity. Hum Mol Genet 2012, 21:3587-3603.

54. Khlistunova I, Biernat J, Wang Y, Pickhardt M, Von Bergen M, Gazova Z Mandelkow E, Mandelkow EM: Inducible expression of Tau repeat domain in cell models of tauopathy: aggregation is toxic to cells but can be reversed by inhibitor drugs. J Biol Chem 2006, 281:1205-1214.

55. Sydow A, Van der Jeugd A, Zheng F, Ahmed T, Balschun D, Petrova O, Drexler D, Zhou L, Rune G, Mandelkow E, D'Hooge R, Alzheimer C, Mandelkow EM: Tau-induced defects in synaptic plasticity, learning, and memory are reversible in transgenic mice after switching off the toxic Tau mutant. J Neurosci 2011, 31:2511-2525.

56. Santa-Maria I, Santpere G, MacDonald MJ, De Barreda EG, Hernandez F, Moreno FJ, Ferrer I, Avila J: Coenzyme Q induces tau aggregation, tau filaments, and Hirano bodies. J Neuropathol Exp Neurol 2008, 67:428-434.

57. Kremer A, Louis JV, Jaworski T, Van Leuven F: GSK3 and Alzheimer's Disease: Facts and Fiction. Front Mol Neurosci 2011, 4:17.

58. Takashima A, Noguchi K, Michel G, Mercken M, Hoshi M, Ishiguro K, Imahori K: Exposure of rat hippocampal neurons to amyloid beta peptide (25-35) induces the inactivation of phosphatidyl inositol-3 kinase and the activation of tau protein kinase $1 /$ glycogen synthase kinase- 3 beta. Neurosci Lett 1996, 203:33-36.

59. Bardai FH, D'Mello SR: Selective toxicity by HDAC3 in neurons: regulation by Akt and GSK3beta. J Neurosci 2011, 31:1746-1751.

60. Kuret J, Congdon EE, Li G, Yin H, Yu X, Zhong Q: Evaluating triggers and enhancers of tau fibrillization. Microsc Res Tech 2005, 67:141-155.

61. Ramachandran G, Udgaonkar JB: Mechanistic studies unravel the complexity inherent in tau aggregation leading to Alzheimer's disease and the tauopathies. Biochemistry 2013, 52:4107-4126.

62. Kotani S, Nishida E, Kumagai H, Sakai H: Calmodulin inhibits interaction of actin with MAP2 and Tau, two major microtubule-associated proteins. J Biol Chem 1985, 260:10779-10783.

63. Kempf M, Clement A, Faissner A, Lee G, Brandt R: Tau binds to the distal axon early in development of polarity in a microtubule- and microfilament-dependent manner. J Neurosci 1996, 16:5583-5592.

64. Maas T, Eidenmuller J, Brandt R: Interaction of tau with the neural membrane cortex is regulated by phosphorylation at sites that are modified in paired helical filaments. J Biol Chem 2000, 275:15733-15740.

65. Farias GA, Munoz JP, Garrido J, Maccioni RB: Tubulin, actin, and tau protein interactions and the study of their macromolecular assemblies. J Cell Biochem 2002, 85:315-324.

66. Steinhilb ML, Dias-Santagata D, Fulga TA, Felch DL, Feany MB: Tau phosphorylation sites work in concert to promote neurotoxicity in vivo. Mol Biol Cell 2007, 18:5060-5068.

67. Biernat J, Gustke N, Drewes G, Mandelkow EM, Mandelkow E: Phosphorylation of Ser262 strongly reduces binding of tau to microtubules: distinction between PHF-like immunoreactivity and microtubule binding. Neuron 1993, 11:153-163.

68. Satoh J, Tabunoki H, Ishida T, Saito Y, Arima K: Ubiquilinimmunoreactivity is concentrated on Hirano bodies and dystrophic neurites in Alzheimer's disease brains. Neuropath Appl Neurobio/ 2013, 39:817-830.
69. Selden SC, Pollard TD: Phosphorylation of microtubule-associated proteins regulates their interaction with actin filaments. J Biol Chem 1983, 258:7064-7071.

70. Griffith LM, Pollard TD: Cross-linking of actin filament networks by self-association and actin-bonding macromolecules. J Biol Chem 1982, 257:9135-9142.

71. Barbato C, Canu N, Zambrano N, Serafino A, Minopoli G, Ciotti MT, Amadoro G, Russo T, Calissano P: Interaction of Tau with Fe65 links tau to APP. Neurobiol Dis 2005, 18:399-408.

72. Vogelsberg-Ragaglia V, Bruce J, Richter-Landsberg C, Zhang B, Hong M, Trojanowski JQ, Lee VM: Distinct FTDP-17 missense mutations in tau produce tau aggregates and other pathological phenotypes in transfected CHO cells. Mol Biol Cell 2000, 11:4093-4104.

73. Krishnamurthy P, Johnson GV: Mutant (R406W) human tau is hyperphosphorylated and does not efficiently bind microtubules in a neuronal cortical cell model. J Biol Chem 2004, 279:7893-7900.

74. Alonso AD, Mederlyova A, Novak M, Grundke-labal I, labal K: Promotion of hyperphosphorylation by frontotemporal dementia tau mutations. J Biol Chem 2004, 279:34873-34881.

75. Hong M, Zhukareva V, Vogelsberg-Ragaglia V, Wszolek Z, Reed L, Miller BI, Geschwind DH, Bird TD, McKeel D, Goate A, Morris JC, Wilhelmsen KC, Schellenberg GD, Trojanowski JQ, Lee VM: Mutation-specific functional impairments in distinct tau isoforms of hereditary FTDP-17. Science 1998 , 282:1914-1917.

76. Feinstein SC, Wilson L: Inability of tau to properly regulate neuronal microtubule dynamics: a loss-of-function mechanism by which tau might mediate neuronal cell death. Biochim Biophys Acta 2005, 1739:268-279.

77. Bramblett GT, Goedert M, Jakes R, Merrick SE, Trojanowski JQ, Lee VM: Abnormal tau phosphorylation at Ser396 in Alzheimer's disease recapitulates development and contributes to reduced microtubule binding. Neuron 1993, 10:1089-1099.

78. Alonso AD, Zaidi T, Novak M, Grundke-labal I, labal K: Hyperphosphorylation induces self-assembly of tau into tangles of paired helical filaments/straight filaments. Proc Natl Acad Sci U S A 2001, 98:6923-6928.

79. Alonso AD, Zaidi T, Novak M, Barra HS, Grundke-lqbal I, lqbal K: Interaction of tau isoforms with Alzheimer's disease abnormally hyperphosphorylated tau and in vitro phosphorylation into disease-like protein. J Biol Chem 2001, 276:37967-37973.

80. Perez M, Hernandez F, Lim F, Diaz-Nido J, Avila J: Chronic lithium treatment decreases mutant tau protein aggregation in a transgenic mouse model. J Alzheimers Dis 2003, 5:301-308.

81. Noble W, Planel E, Zehr C, Olm V, Meyerson J, Suleman F, Gaynor K, Wang L, LaFrancois J, Feinstein B, Burns M, Krishnamurthy P, Wen Y, Bhat R, Lewis J, Dickson D, Duff K: Inhibition of glycogen synthase kinase-3 by lithium correlates with reduced tauopathy and degeneration in vivo. Proc Natl Acad Sci U S A 2005, 102:6990-6995.

82. Alonso AD, Adel C, Li B, Grundke-labal I, labal K: Polymerization of hyperphosphorylated tau into filaments eliminates its inhibitory activity. Proc Natl Acad Sci U S A 2006, 103:8864-8869.

83. Jeganathan S, Hascher A, Chinnathambi S, Biernat J, Mandelkow EM, Mandelkow E: Proline-directed pseudo-phosphorylation at AT8 and PHF1 epitopes induces a compaction of the paperclip folding of Tau and generates a pathological (MC-1) conformation. J Biol Chem 2008, 283:32066-32076.

84. Eidenmüller J, Fath T, Hellwig A, Reed J, Sontag E, Brandt R: Structural and functional implications of tau hyperphosphorylation: information from phosphorylation-mimicking mutated tau proteins. Biochemistry 2000 39:13166-13175.

85. Cho JH, Johnson GV: Primed phosphorylation of tau at Thr231 by glycogen synthase 3 beta (GSK3beta) play a critical role in regulating tau's ability to bind and stabilize microtubules. J Neurochem 2004, 88:349-358.

86. Li T, Paudel HK: Glycogen synthase kinase 3beta phosphorylates Alzheimer's disease-specific Ser396 of microtubule-associated protein tau by a sequential mechanism. Biochemistry 2006, 45:3125-3133.

87. Sengupta A, Novak M, Grundke-lqbal I, lqbal K: Regulation of phosphorylation of tau by cyclin-dependent kinase 5 and glycogen kinase-3 at substrate level. FEBS Lett 2006, 580:5925-5933.

88. Liu SJ, Zhang JY, Li HL, Fang ZY, Wang Q, Deng HM, Gong CX, Grundke-lqbal I, lqbal K: Tau becomes a more favorable substrate for GSK-3 when it is prephosphorylated by PKA in rat brain. J Biol Chem 2004, 279:50078-50088. 
89. Shahani N, Subramaniam S, Wolf T, Tackenberg C, Brandt R: Tau aggregation and progressive neuronal degeneration in the absence of changes in spine density and morphology after targeted expression of Alzheimer's disease-relevant tau constructs in organotypic hippocampal slices. J Neurosci 2006, 26:6103-6114.

90. Morris M, Maeda S, Vossel K, Mucke L: The many faces of tau. Neuron 2011, 70:410-426.

91. Von Bergen M, Friedhoff P, Biernat J, Heberle J, Mandelkow EM, Mandelkow E: Assembly of tau protein into Alzheimer paired helical filaments depends on a local sequence motif ((306)VQIVYK(311)) forming beta structure. Proc Natl Acad Sci U S A 2000, 97:5129-5134.

92. Chang E, Kim S, Yin H, Nagaraja HN, Kuret J: Pathogenic missense MAPT mutations differentally modulate tau aggregation propensity at nucleation and extension steps. J Neurochem 2008, 107:1113-1123.

93. Dayanandan R, Van Slegtenhorst M, Mack TG, Ko L, Yen SH, Leroy K, Brion $J P$, Anderton $\mathrm{BH}$, Hutton M, Lovestone S: Mutations in tau reduce its microtubule binding properties in intact cells and affect its phosphorylation. FEBS Lett 1999, 446:228-232

94. Connell JW, Gibb GM, Betts JC, Blackstock WP, Gallo J, Lovestone S, Hutton $\mathrm{M}$, Anderton BH: Effects of FTDP-17 mutations on the in vitro phosphorylation of tau by glycogen synthase kinase 3beta identified by mass spectrometry demonstrate certain mutations exert long-range conformational changes. FEBS Lett 2001, 493:40-44.

95. Gauthier-Kemper A, Weissmann C, Golovyashkina N, Sebo-Lemke Z, Drewes G, Gerke V, Heinisch JJ, Brandt R: The frontotemporal dementia mutation R406W blocks tau's interaction with the membrane in an annexin A2-dependent manner. J Cell Biol 2011, 192:647-661.

96. Wszolek ZK, Tsuboi Y, Ghetti B, Pickering-Brown S, Baba Y, Cheshire WP: Frontotemporal dementia and parkinsonism linked to chromosome 17 (FTDP-17). Orphanet J Rare Dis 2006, 1:30.

97. Furukawa R, Fechheimer M: Role of the Dictyostelium $30 \mathrm{kDa}$ protein in actin bundle formation. Biochemistry 1996, 35:7224-7232.

98. Kinoshita A, Whelan CM, Berezovska O, Hyman BT: The gamma secretase-generated carboxyl-terminal domain of the amyloid precursor protein induces apoptosis via Tip60 in H4 cells. J Biol Chem 2002, 277:28530-28536.

99. Summers SA, Kao AW, Kohn AD, Backus GS, Roth RA, Pessin JE, Birnbaum MJ: The role of glycogen synthase kinase 3beta in insulin-stimulated glucose metabolism. J Biol Chem 1999, 274:17934-17940.

100. Stambolic V, Woodgett JR: Mitogen inactivation of glycogen synthase kinase-3b in intact cells via serine 9 phosphorylation. Biochem J 1994 303:701-704.

101. Fath T, Eldenmüller J, Brandt R: Tau-mediated cytotoxicity in a pseudohyperphosphorylation model of Alzheimer's disease. J Neurosci 2002, 22:9733-9741.

102. Hedgepeth CM, Conrad LJ, Zhang J, Huang HC, Lee VM, Klein PS: Activation of the Wnt signaling pathway: a molecular mechanism for lithium action. Dev Biol 1997, 185:82-91.

103. Gibson PH: Light and electron microscopic observations on the relationship between Hirano bodies, neuron and glial perikarya in the human hippocampus. Acta Neuropathol 1978, 42:165-171.

104. Garwood CJ, Pooler AM, Atherton J, Hanger DP, Noble W: Astrocytes are important mediators of Abeta-induced neurotoxicity and tau phosphorylation in primary culture. Cell Death Dis 2011, 2:e167.

105. Dickey CA, Erickson J, Kamal A, Burrows F, Kasibhatla S, Eckman CB, Hutton $M$, Petrucelli L: Development of a high throughput drug sceening assy for detection of changes in tau levels-proof of concept with HSP90 inhibitors. Curr Alzheimer Res 2005, 2:231-238.

106. Bretteville A, Ando K, Ghestem A, Loyens A, Begard S, Beauvillian JC, Sergant N, Hamdane M, Buee L: Two-dimensional electrophoresis of tau mutants reveals specific phosphorylation pattern likely linked to early tau conformational changes. PLoS One 2009, 4:e4843.

107. Barghorn S, Biernat J, Mandelkow E: Purification of Recombinant Tau Protein and Preparation of Alzheimer-Paired Helical Filaments In Vitro. In Amyloid Proteins: Methods and Protocols. Volume 299. Edited by Sigurdsson EM. Totowa, NJ: Humana Press; 2004:35-51.

108. Spudich JA, Watt S: The regulation of rabbit skeletal muscle contraction. J Biol Chem 1971, 246:4866-4871.

109. MacLean-Fletcher SD, Pollard TD: Identification of a factor in conventional muscle actin preparations which inhibits actin filament self-association. Biochem Biophys Res Commun 1980, 96:18-27.
110. Smith PK, Krohn Rl, Hermanson GT, Mallia AK, Gartner FH, Provenzano MD, Fujimoto EK, Goeke NM, Olson BJ, Klenk DC: Measurement of protein using bicinchoninic acid. Anal Biochem 1985, 150:76-85.

111. Fechheimer M: The Dictyostelium discoideum 30,000-dalton protein is an actin filament-bundling protein that is selectively present in filopodia. J Cell Biol 1987, 104:1539-1551.

doi:10.1186/1471-2202-15-74

Cite this article as: Spears et al:: Hirano bodies differentially modulate cell death induced by tau and the amyloid precursor protein intracellular domain. BMC Neuroscience 2014 15:74.

\section{Submit your next manuscript to BioMed Central and take full advantage of:}

- Convenient online submission

- Thorough peer review

- No space constraints or color figure charges

- Immediate publication on acceptance

- Inclusion in PubMed, CAS, Scopus and Google Scholar

- Research which is freely available for redistribution

Submit your manuscript at www.biomedcentral.com/submit
C BioMed Central 